Research Article

\title{
Electromagnetic Forces and Mechanical Responses of Stator Windings before and after Rotor Interturn Short Circuit in Synchronous Generators
}

\author{
Gui-Ji Tang, ${ }^{1}$ Hong-Chun Jiang, ${ }^{1}$ Yu-Ling He $\mathbb{D}^{\mathbb{D}},{ }^{1}$ and Qing-Fa Meng ${ }^{2}$ \\ ${ }^{1}$ Department of Mechanical Engineering, North China Electric Power University, Baoding, China \\ ${ }^{2}$ Zhongtong Bus Holding Co., Ltd., Liaocheng, China \\ Correspondence should be addressed to Yu-Ling He; heyuling1@163.com
}

Received 30 July 2020; Revised 9 December 2020; Accepted 20 December 2020; Published 31 December 2020

Academic Editor: Daniela Addessi

Copyright (C) 2020 Gui-Ji Tang et al. This is an open access article distributed under the Creative Commons Attribution License, which permits unrestricted use, distribution, and reproduction in any medium, provided the original work is properly cited.

\begin{abstract}
This paper studies the stator winding electromagnetic force behaviors before and after rotor inter-turn short circuit (RISC) in synchronous generator. Different from other studies, this paper not only studies the electromagnetic force characteristics, but also investigates the mechanical responses, the damage regularity, and the countermeasure of the stator winding. Firstly, formulas of electromagnetic force online and end part are obtained. Then, a 3D finite element model of a 3-pair-pole simulation generator is applied to get the electromagnetic force, and the dangerous stator slot is found. Finally, the mechanical response of each end winding is acquired, and especially the directional deformations of nose part are calculated. It shows that the occurrence of RISC will bring in times of rotor rotating frequency components to electromagnetic force, but the DC component and $2 p$ times of rotor rotating frequency components are still the main that will be decreased. Additionally, the winding insulation wear in the same layer is more serious than that in a different layer, nose fatigue fracture begins with the center, and nose insulation wear starts from the top.
\end{abstract}

\section{Introduction}

With the increase of the generator capacity, the winding electromagnetic force that generates alternating stresses and stimulates vibrations becomes larger as well. Consequently, the winding will endure worse fatigue fracture and insulation wearing.

By far, scholars have made a lot of efforts in studying the winding electromagnetic force properties. For instance, Merkhouf et al. proposed a quasi-3D electromagnetic model to compute the forces on the conductor bars in hydrogenerators [1], while Sanosian et al. demonstrated how saturation of the stator teeth, actual magnetic field distribution inside the slot, eddy current in the damper bars, and the shape of the salient poles impacted the electromagnetic forces in the slot [2]. According to Biot-Savart Law, the mirror image method was employed to analyze the end magnetic field, and the electromagnetic force of the end winding was acquired by using the ampere force formula [3]. Meanwhile, Ghaempanah and Faiz reviewed the calculation methods for the magnetic force exerted on the stator end winding comprehensively [4]. Comparing the finite element method (FEM) with Biot-Savart method, it has been found that FEM was more effective for electromagnetic analysis [5]. Andrey Tatevosyan and Fokina made the study on the electromagnetic field of a synchronous generator based on the three-phase induction machine [6]. The 2D field-circuit-motion coupling analysis was employed to calculate the stator current in inverter-fed induction machine, as well as hydrogenerators. And the distribution of electromagnetic force on stator windings was calculated $[7,8]$. Comparatively, Stancheva and Iatcheva employed the 3D FEM to analyze the electromagnetic force distribution characteristics of the stator winding in turbo-generators $[9,10]$. Chong et al. explored the electromagnetic force of involute part of the end windings by 3D FEM on nuclear 
generator, and the vulnerable parts of double windings on different layers are obtained [11]. In Ref. [12], the electromagnetic forces of transformer windings in the occurrence of magnetic flux shunts were studied based on the finite element method, which was validated by a double Fourier series method. An advanced FEM has been used in [13] by defining the superconductivity characteristic, and the results show the efficiency of the applied method to mitigate the leakage flux and electromagnetic forces of the windings. It has been found that, under the steady-state condition in an induction motor, there were radial, circumferential, and axial forces consisting of a constant component and a sinusoidal component at the double frequency [14]. Besides, the armature winding properties, such as the number of winding layers and the slot fill factor, will affect the magnetomotive force harmonic components, leading to the magnetic field changes. Consequently, the electromagnetic force on stator windings will be influenced [15]. It shows that choosing a right coil pitch may reduce the harmonic contents and improve the conductor utilization ratios effectively [16].

At the meantime, Stermecki et al. calculated the mechanical deformations of end winding in three-phase induction machines under operating load condition, using a 3D FEM [17]. Fang et al. analyzed the electromagnetic forces and stresses on the stator end windings of an electrical submersible motor during the starting transient operation [18]. Normally, the nose top, the middle point of the involute, and the joint between the line part and the end part are the most dangerous three positions since they get the max stresses and deformations in a $600 \mathrm{MW}$ turbo-generator [19]. Meanwhile, the forces on the knuckle part of the upper part of a coil end are larger than those on the other parts. In addition, the constant components and the amplitudes of the sinusoidal components of the forces on the same positions of different coil ends in a phase belt are nearly different on induction machine.

In summary, most of the studies focus on the winding electromagnetic force properties in normal conditions, and few of them have considered the electromagnetic force behavior in faulty cases. Albanese et al. and Zhao et al. studied on the end winding electromagnetic force spectrum characteristics, modal, stress, deformation, and main vibration shape in inter-phase short circuit conditions [20, 21]. However, the rotor inter-turn short circuit (RISC) is generally neglected because the generator can still run for a long term until the planned maintenance point when the fault degree is weak. Actually, it occurs from time to time due to many causes such as the frictions by the residual metal particles in the slots and in-proper assembling, and in this case, the exciting electromagnetic force, as well as other typical faulty properties, is different from that in the normal conditions. For example, Nadarajan et al. proposed a hybrid modeling approach to model synchronous generator by combining the dq0 modeling with the winding function approach for turn-to-turn short circuit [22]. Yucai and Yonggang analyzed the difference between the virtual power and the actual electromagnetic power when RISC occurs [23], while Valavi et al. and Yun et al. studied the effect of the fault on air gap flux density and the monitoring method based on the distorted flux density [24, 25]. Furthermore, the electromagnetic characteristics and mechanical characteristics, as well as the correlative variety of the electrical parameters induced after rotor inter-turn short circuit on turbine generator, are analyzed by Wan et al. [26-28]. Then, the BP neural network method and the sensorless online detection method were proposed to diagnosis rotor winding inter-turn short circuit fault $[29,30]$.

Actually, the authors have also proposed a prestudy on the electromagnetic force, as well as the mechanical responses of the stator end windings in a RISC case; more details can be found in [31]. However, the theoretical model in this prestudy is somewhat complex and hard to understand, while the FE model, as well as the calculation result, is not accurate enough (only part of the stator/rotor/winding is established in the FE model). Moreover, there was no experiment study for the validation in this aforementioned work. As an improvement, in this paper, we improve both the theoretical model and the 3D FE model and present an experiment study, to obtain a more accurate result. The remainder of this paper is arranged as follows. Section 2 puts forward the theoretical analysis of the winding electromagnetic force for multi-pair-pole generator. Section 3 calculates the electromagnetic force distribution on the line and end part, respectively, with FEM, and it is more reasonable for comparing with the experimental results as the vibration of end part winding is mainly caused by electromagnetic force of the end. At the same time, it carries out the experiment study and validates the correction of theoretic and simulated analysis. Then, the mechanical response analysis is illustrated in Section 4, and a detailed analysis on the directional deformations and the insulation wearing regularity is specifically carried out for the nose part considering the complex structure and weakness. Finally, main conclusions are drawn in Section 5.

\section{Theoretical Analysis}

2.1. Electromagnetic Force. The MMF in generator has been obtained in Ref. [32], but the situation is just for one pair of poles. Since there are some differences between the one-pair and multipair poles, hereafter, we particularly carried out the derivation for the multi-pair-pole generators.

For the sake of convenience, in this paper, we ignore the higher harmonics whose values are relatively much smaller, and the normal MMF can be written as

$$
\left\{\begin{array}{l}
f\left(\alpha_{m}, t\right)=F_{s} \cos \left(\omega t-p \alpha_{m}-\psi-0.5 \pi\right)+F_{r} \cos \left(\omega t-p \alpha_{m}\right) \\
=F_{c} \cos \left(\omega t-p \alpha_{m}-\beta\right)=F_{c} \cos \left(p \omega_{r} t-p \alpha_{m}-\beta\right) \\
F_{c}=\sqrt{F_{s}^{2} \cos ^{2} \psi+\left(F_{r}-F_{s} \sin \psi\right)^{2}} \\
\beta=\arctan \frac{F_{s} \cos \psi}{F_{r}-F_{s} \sin \psi},
\end{array}\right.
$$


where $\alpha_{m}$ is the mechanical angle to indicate the circumferential position; see Figure 1(d). $p$ is the number of the pole pairs, $\omega$ is the electrical angular frequency $\left(\omega=p \omega_{r}, \omega_{r}\right.$ is the mechanical angular frequency of the rotor), $\Psi$ is the internal power-angle of generator, $F_{s}$ and $F_{r}$ are the 1st harmonic MMF of the stator and the rotor, respectively, and $F_{c}$ is the vector summation of $F_{s}$ and $F_{r}$ as indicated in Figures 1(a) and $1(b)$.

For the sake of clarification, we assume that the interturn short circuit takes place on the position of $\beta^{\prime}$, as illustrated in Figure 1(d). $I_{f}$ is the exciting current, and $n_{m}$ is the number of the short circuit turns. The impact of RISC on MMF is equal to adding an inverse MMF to the normal one $[33,34]$. For better comprehension, the inversed MMF produced by the short circuit turns is also shown in Figure 1(c). Based on the magnetic flux conservation principle, the reversed MMF can be expressed as

$$
F_{d}\left(\alpha_{m}\right)= \begin{cases}-\frac{I_{f} n_{m}\left(\pi-\beta^{\prime}\right)}{\pi}, & -\beta^{\prime} \leq \alpha_{m} \leq \beta^{\prime}, \\ \frac{I_{f} n_{m} \beta^{\prime}}{\pi}, & \text { other, }\end{cases}
$$

where $F_{d}$ can be expanded by Fourier series as

$$
F_{d}\left(\alpha_{m}\right)=a_{0}+\sum_{n=1}^{\infty} a_{n} \cos \left(n \alpha_{m}\right)+b_{n} \sin \left(n \alpha_{m}\right),
$$

with

$$
\left\{\begin{array}{l}
a_{0}=\frac{1}{2 \pi} \int_{-\pi}^{\pi} F_{d}\left(\alpha_{m}\right) d \alpha_{m}=0 \\
a_{n}=\frac{1}{\pi} \int_{-\pi}^{\pi} F_{d}\left(\alpha_{m}\right) \cos \left(n \alpha_{m}\right) d \alpha_{m}=-\frac{2 I_{f} n_{m} \sin \left(n \beta^{\prime}\right)}{n \pi} \\
b_{n}=\frac{1}{\pi} \int_{-\pi}^{\pi} F_{d}\left(\alpha_{m}\right) \sin \left(n \alpha_{m}\right) d \alpha_{m}=0 .
\end{array}\right.
$$

Then, $F_{d}$ can be reduced to

$$
\left\{F_{d}\left(\alpha_{m}\right)=-\sum_{n=1}^{\infty} F_{d n} \cos n \alpha_{m}, F_{d n}=\frac{2 I_{f} n_{m} \sin \left(n \beta^{\prime}\right)}{n \pi} .\right.
$$

Considering that the rotor is rotating at $\omega_{r}$, the reversed MMF at position $\alpha_{m}$ can be finally described as

$$
F_{d}\left(\alpha_{m}\right)=-\sum_{n=1}^{\infty} F_{d n} \cos \left(n \omega_{r} t-n \alpha_{m}\right)
$$

As indicated in Figure 1(b), the MMF after RISC can be written as

$$
\left\{\begin{array}{l}
f\left(\alpha_{m}, t\right)=F_{s} \cos \left(p \omega_{r} t-p \alpha_{m}-\psi-0.5 \pi\right)+\left(F_{r}-F_{d p}\right) \cos \left(p \omega_{r} t-p \alpha_{m}\right)-\sum_{n=1, n \neq p}^{\infty} F_{d n} \cos \left(n \omega_{r} t-n \alpha_{m}\right) \\
=F_{c s} \cos \left(p \omega_{r} t-p \alpha_{m}-\gamma\right)-\sum_{n=1, n \neq p}^{\infty} F_{d n} \cos \left(n \omega_{r} t-n \alpha_{m}\right) \\
F_{c s}=\sqrt{F_{s}^{2} \cos ^{2} \psi+\left(F_{r}-F_{d p}-F_{s} \sin \psi\right)^{2}} \\
\gamma=\operatorname{arctg} \frac{F_{s} \cos \psi}{F_{r}-F_{d p}-F_{s} \sin \psi}
\end{array}\right.
$$

where $F_{c s}$ is the vector summation of $F_{s}, F_{r}$ and $F_{d p}$, as indicated in Figure 1(b).

Comparing Figure 1(c) and equation (7) with the result in Ref. [32] (Figure 2 and equation (11) in this reference), it is shown that the multi-pair-pole generators will have a different MMF distribution from that of one-pair generators.

The magnetic flux density (MFD) is composed of the MMF and the permeance per unit area (PPUA), and it can be obtained by multiplying these two [33].

$$
B\left(\alpha_{m}, t\right)=f\left(\alpha_{m}, t\right) \Lambda_{0},
$$

where $\Lambda_{0}$ is the PPUA $\left(\Lambda_{0}=\mu_{0} / g_{0}\right), g_{0}$ is the average value of the radial air-gap length between the stator core and the rotor core (as shown in Figure $1(\mathrm{~d})$ ), and $\mu_{0}$ is the permeability of air/vacuum.

Neglecting the affection of windings connection, the current of winding on $\alpha_{m}$ can be written as

$$
I\left(\alpha_{m}, t\right)=\frac{B\left(\alpha_{m}, t\right) l v}{z}=\frac{f\left(\alpha_{m}, t\right) \Lambda_{0} l v}{z},
$$

where $l$ and $v$ are the effective length and the line velocity of the magnetic flux cutting the stator bar, and $Z$ is the reactance of the stator winding. 


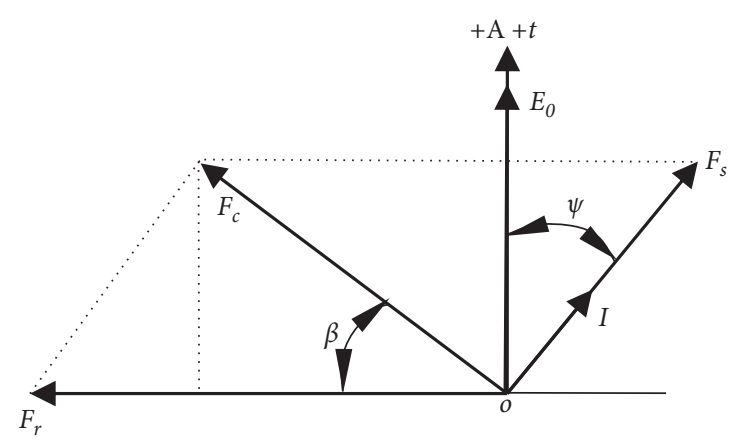

(a)
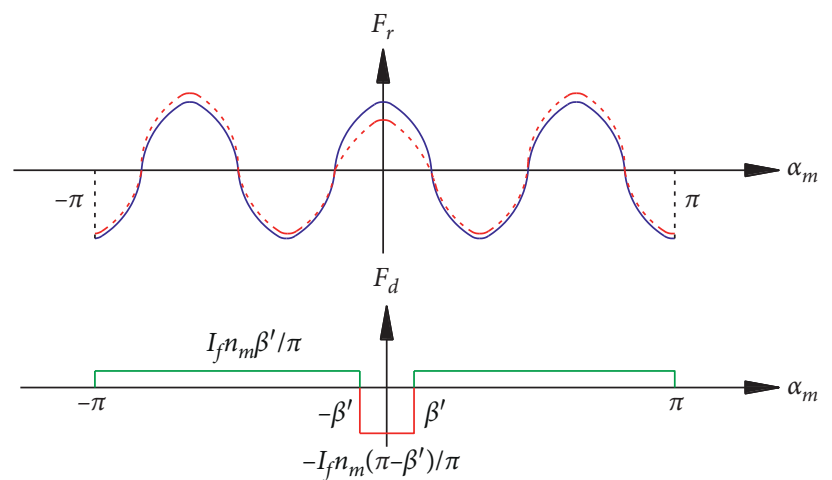

- Normal

- - RISC

(c)

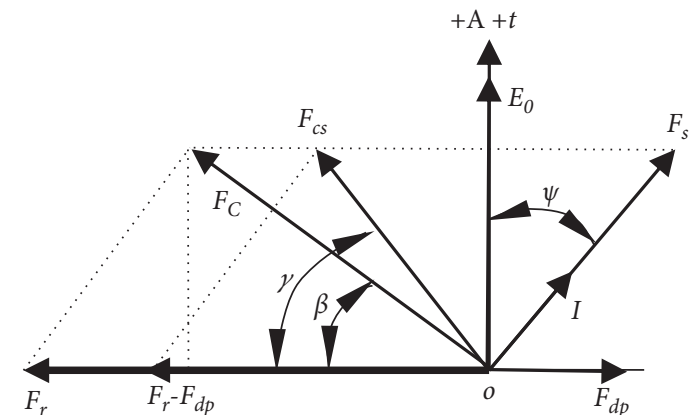

(b)

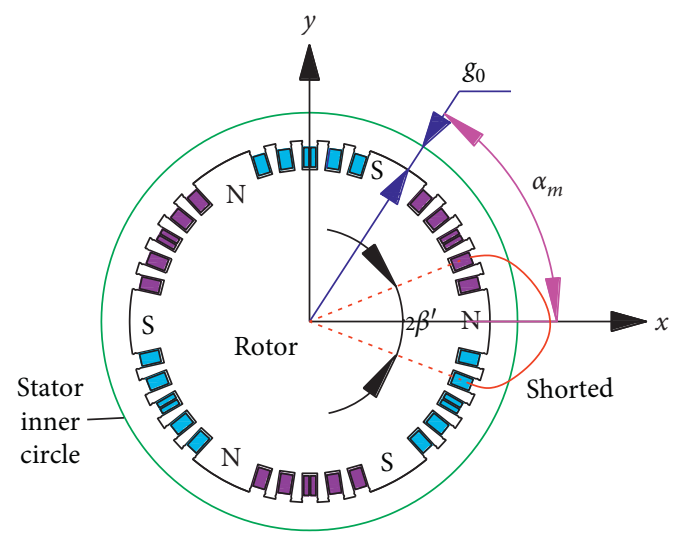

(d)

FIGURE 1: MMFs before and after RISC: (a) normal condition, (b) RISC case, (c) inversed MMF (down) and Rotor MMF (up), and (d) schematic diagram of air gap.

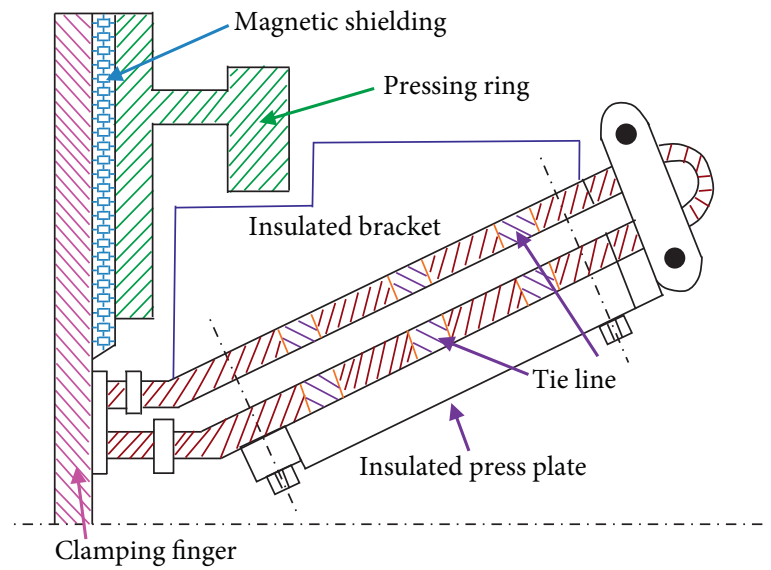

(a)

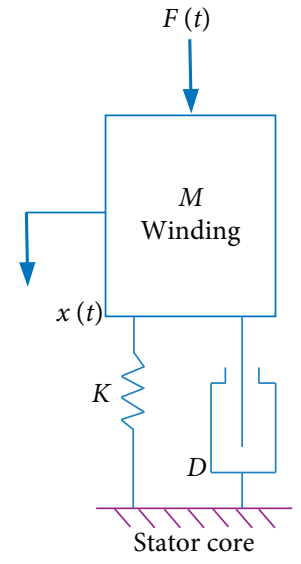

(b)

FIGURE 2: End winding model: (a) end winding support; (b) simplified mechanics model in radial direction. 
According to the electromagnetic induction law, the force on the winding whose upper line (see Figure 3(f)) is at the circumferential position $\alpha_{m}$ can be written as

$$
\begin{aligned}
& F_{L}\left(\alpha_{m}, t\right)=B\left(\alpha_{m}, t\right) I\left(\alpha_{m}, t\right) l=\frac{f^{2}\left(\alpha_{m}, t\right) \Lambda_{0}^{2} l^{2} v}{Z} \\
& =\left\{\begin{array}{l}
\frac{F_{c}^{2} \Lambda_{0}^{2} l^{2} v}{2 Z}\left[\cos \left(2 p \omega_{r} t-2 p \alpha_{m}-2 \beta\right)+1\right], \\
F_{c s}^{2} \cos 2\left(p \omega_{r} t-p \alpha_{m}-\gamma\right)+\sum_{n=1, n \neq p}^{\infty} F_{d n}^{2} \cos 2\left(n \omega_{r} t-n \alpha_{m}\right)+F_{c s}^{2}+\sum_{n=1, n \neq p}^{\infty} F_{d n}^{2} \\
\frac{\Lambda_{0}^{2} l^{2} v}{2 Z}\left\{\begin{array}{c}
-\sum_{n=1, n \neq p}^{\infty} 2 F_{c s} F_{d n} \cos \left[(p+n)\left(\omega_{r} t-\alpha_{m}\right)-\gamma\right]-\sum_{n=1, n \neq p}^{\infty} 2 F_{c s} F_{d n} \cos \left[(p-n)\left(\omega_{r} t-\alpha_{m}\right)-\gamma\right] \\
+\sum_{n=1, n \neq p}^{\infty} \sum_{k=1, k \neq n}^{\infty} F_{d n} F_{d k} \cos \left[(n-k)\left(\omega_{r} t-\alpha_{m}\right)\right]+\sum_{n=1, n \neq p}^{\infty} \sum_{k=1, k \neq n}^{\infty} F_{d n} F_{d k} \cos \left[(n+k)\left(\omega_{r} t-\alpha_{m}\right)\right]
\end{array}\right\}, \quad \text { RISC, }
\end{array}\right. \\
& \left\{\begin{array}{l}
\overline{F_{E}\left(\alpha_{m}, t\right)}=\int_{l_{\text {end }}} \overline{F_{E k}\left(\alpha_{m}, t\right)} d l_{\text {end }}, \\
F_{E k}\left(\alpha_{m}, t\right)=k_{e} B\left(\alpha_{m}+\alpha_{k}, t\right) I\left(\alpha_{m}, t\right) \sin \theta_{k}=k_{e} \Lambda_{0}^{2} l v f\left(\alpha_{m}+\alpha_{k}, t\right) f\left(\alpha_{m}, t\right) \frac{\sin \theta_{k}}{Z} \\
{\left[\begin{array}{c}
F_{c s}^{2} \cos 2\left(p \omega_{r} t-2 p \alpha_{m}-2 \gamma-p \alpha_{k}\right)+\sum_{n=1, n \neq p}^{\infty} F_{d n}^{2} \cos \left(2 n \omega_{r} t-2 n \alpha_{m}-n \alpha_{k}\right)+F_{c s}^{2} \cos p \alpha_{k}+\sum_{n=1, n \neq p}^{\infty} F_{d n}^{2} \cos n \alpha_{k} \\
-\sum_{n=1, n \neq p}^{\infty} F_{c s} F_{d n} \cos \left[(p+n)\left(\omega_{r} t-\alpha_{m}\right)-\gamma-p \alpha_{k}\right]-\sum_{n=1, n \neq p}^{\infty} F_{c s} F_{d n} \cos \left[(p-n)\left(\omega_{r} t-\alpha_{m}\right)-\gamma-p \alpha_{k}\right] \\
\frac{k_{e} F_{c s}^{2} \Lambda_{0}^{2} l v \sin \theta_{k}}{2 Z}\left[\begin{array}{c}
\left.\cos \left(2 p \omega_{r} t-2 p \alpha_{m}-2 \beta-p \alpha_{k}\right)+\cos p \alpha_{k}\right], \\
2 Z
\end{array}\right. \\
+\sum_{n=1, n \neq p}^{\infty} F_{c s} F_{d n} \cos \left[(p+n)\left(\omega_{r} t-\alpha_{m}\right)-\gamma-n \alpha_{k}\right]-\sum_{n=1, n \neq p}^{\infty} F_{c s} F_{d n} \cos \left[(p-n)\left(\omega_{r} t-\alpha_{m}\right)-\gamma+n \alpha_{k}\right]
\end{array}\right.}
\end{array}\right.
\end{aligned}
$$

where $F_{E}$ and $F_{L}$ are the forces on the end part and the line part, respectively, and $F_{E k}$ is the electromagnetic force at an arbitrary point $K$ of the end winding, and a bar to indicate a space vector. $l_{\text {end }}$ is the curve of the end part, $\left(\alpha_{m}+\alpha_{k}\right)$ refers to circumferential position of point $K, k_{e}$ is the MFD factor of end point $K$, and $\theta_{k}$ is the angle between the current vector and MFD.

As indicated in equations (10) and (11), in normal conditions, the electromagnetic force on both the line part and the end part includes mainly a DC component and a harmonic component at $2 p \omega_{r}$ (that is, $2 \omega$ ), which accords with the result presented in Ref. [9]. It is also suggested that the electromagnetic force in RISC case has much more components, and the frequencies of these new components are times of the rotor's mechanical rotating frequency $\omega_{r}$. Because the amplitude of $F_{d n}$ is much smaller, especially when the harmonic order $n$ goes larger, these new components are mainly weak harmonics, so the DC and the $2 \omega$ component are still the main ones. However, their amplitudes are both decreased due to the reduction of the MMF by the short circuit, as shown in Figures 1 (a) and 1(b), and $F_{c s}$ is smaller than $F_{c}$.

Although RISC decreases the primary components (DC and $2 \omega$ ), it brings in new harmonics that could be closer to the natural frequencies of the winding. Consequently, the winding is potential to endure the sympathetic vibration, 


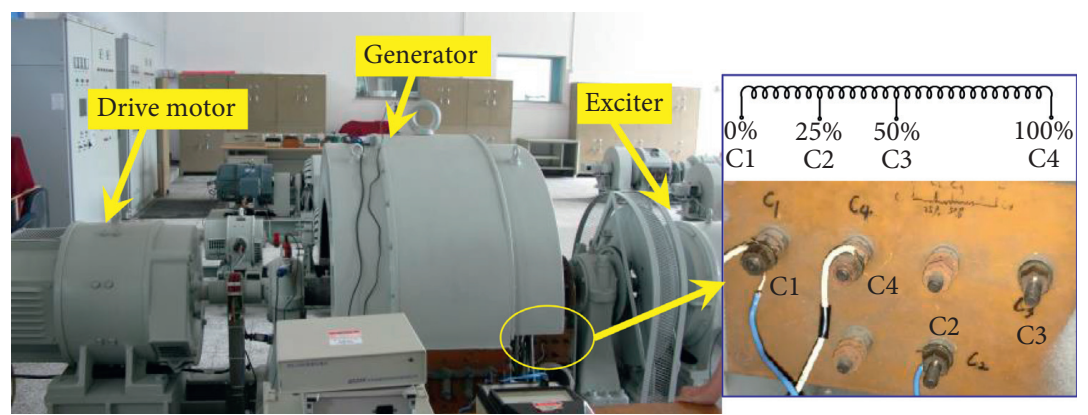

(a)

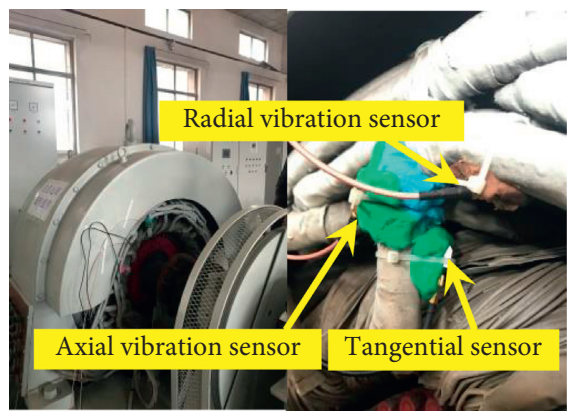

(b)

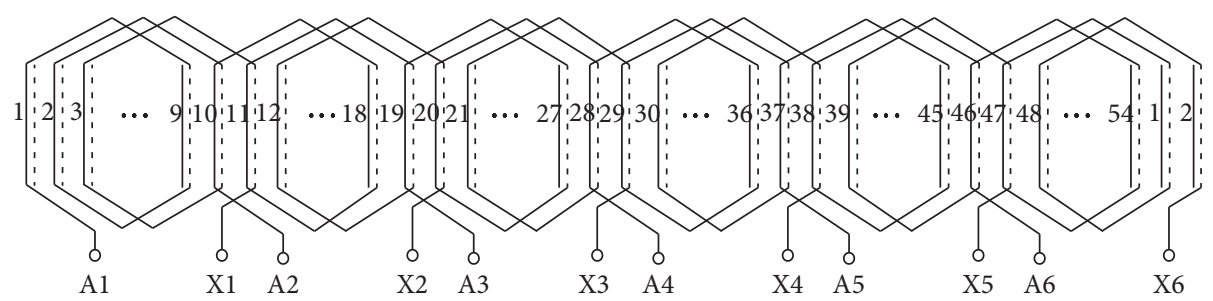

(c)

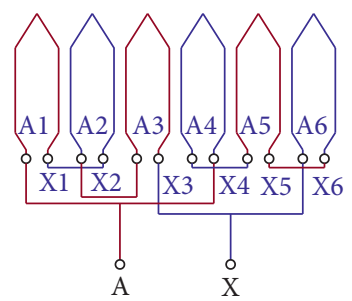

(d)

Figure 3: Continued. 


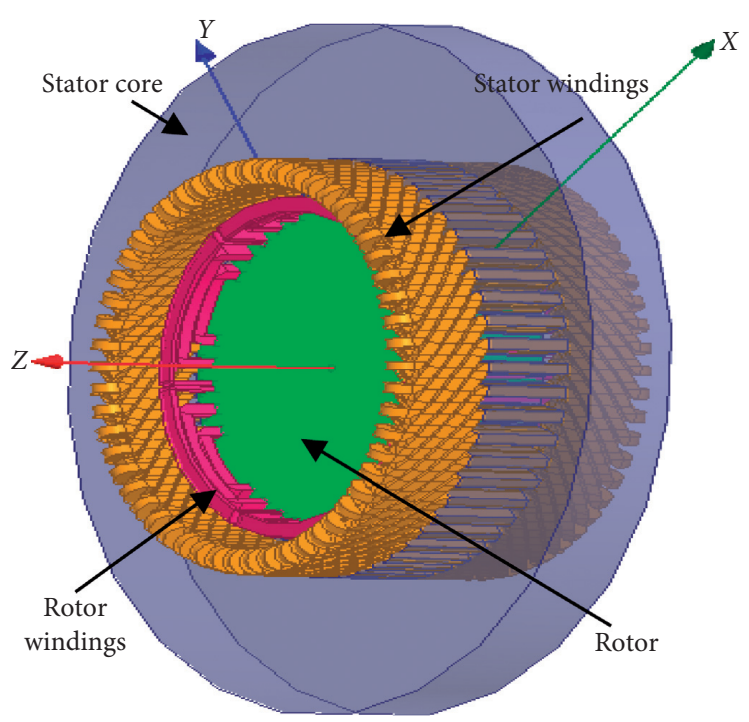

(e)

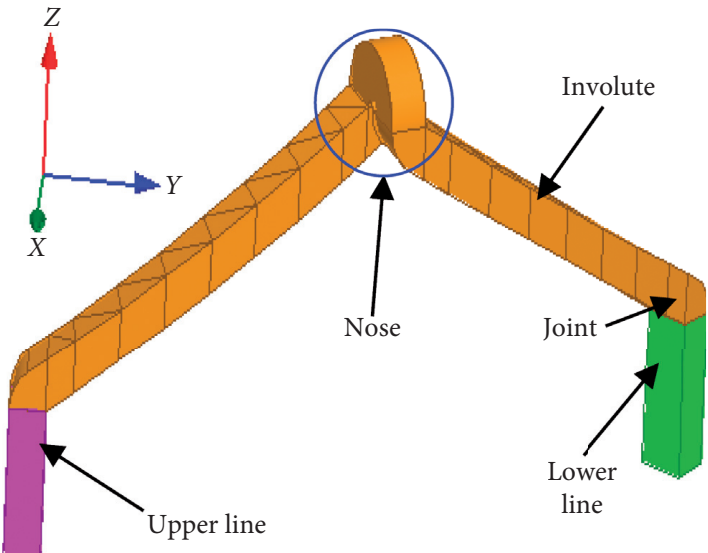

(f)

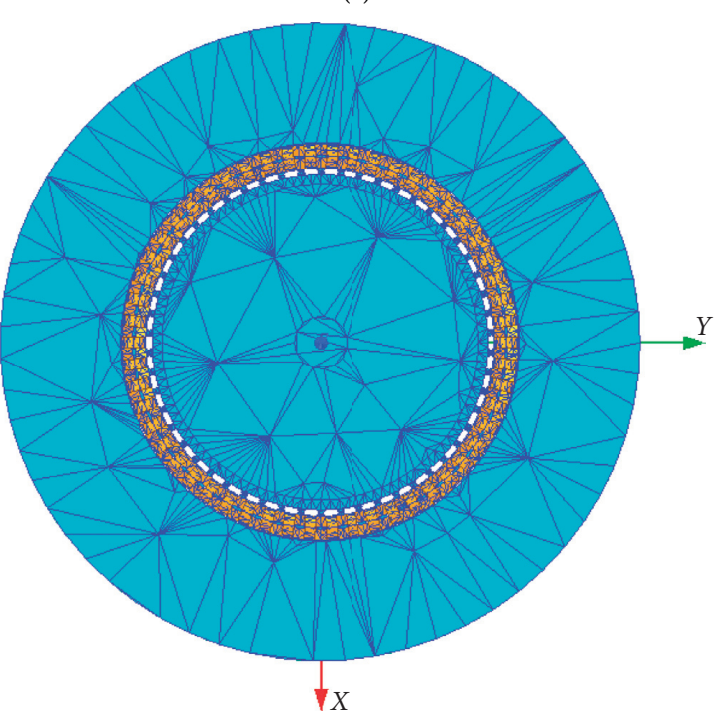

(g)

Figure 3: Continued. 


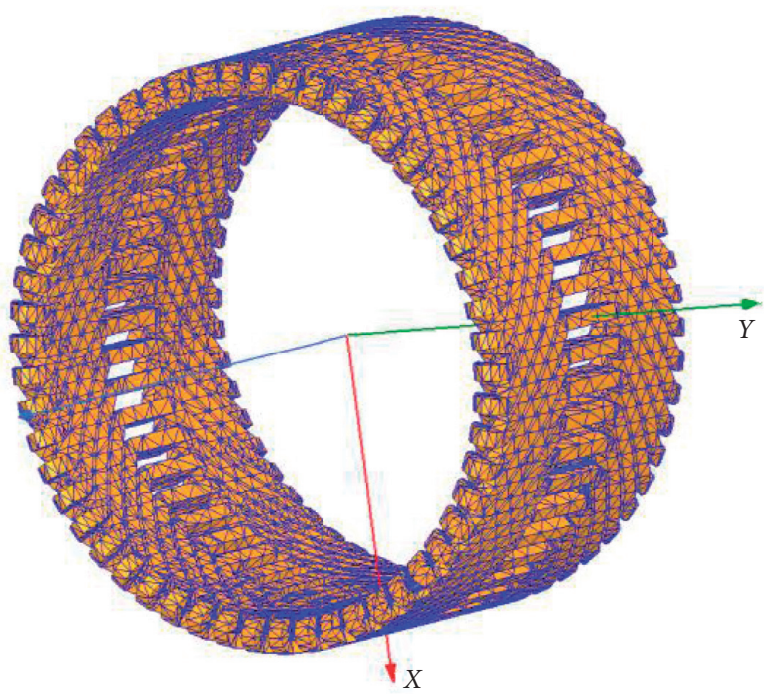

(h)

FIGURE 3: MJF-30-6 prototype generator: (a) picture of generator set, (b) vibration sensor set, (c) winding distribution of Phase A, (d) winding connection of Phase A, (e) 3D physical model, (f) structure of stator winding, (g) mesh solution of generator model, and (h) mesh solution of stator winding.

which is of high probability to damage the winding in both the metal structure and the insulation properties. Therefore, it is of great significance to study these new force components. For the sake of comparison reference, the amplitudes of the former 6 force harmonics of a 3-pair poles synchronous generator, which is the study object in the next section, are listed in Table 1.

2.2. Mechanical Response. The structure of the stator end winding is illustrated in Figure 2(a). The electromagnetic force can cause the end of stator winding to vibrate and bring about insulation wear, while the line part of stator winding is fixed in the stator slot and fastened with slot wedge. Hence, the influence of line part's electromagnetic force on the end part can be ignored. The mechanical model of statorwinding system is shown in Figure 2(b). The dynamic equation can be listed as follows:

$$
M x^{\prime \prime}(t)=F_{E k}\left(\alpha_{m}, t\right)-D x^{\prime}(t)-K x(t),
$$

where $M$ is the mass of the stator winding end part, $D$ is the damping provided by the tie lines, $K$ is the stiffness provided by both the winding's material elasticity and the tie line, and $x(t)$ is the displacement/movement matrix of the mass points.

Specifically, the electromagnetic force excitation on the end winding corresponds to the response of the first order vibration. The displacement represents the amplitude of vibration. As the electromagnetic force is periodic, the corresponding response will also be periodic, and this periodicity of the end winding displacement is represented by vibration. The vibration will aggravate the winding insulation wear and reduce the service life of generator.

Hereafter, we will carry out the finite element calculation through electromagnetics-mechanical coupling and the experiment study. The finite element analysis includes both the electromagnetic force and the mechanical response calculation, while the experiment study mainly tests the winding vibrations (response of the exciting forces). More details can be found in Section 3.

\section{FEA and Experimental Study}

3.1. FEA and Experiment Setup. We employ the MJF-30-6 type prototype generator as the study object as illustrated in Figure 3(a). It is in the State Key Laboratory of Alternate Electrical Power systems with Renewable Energy Sources, P.R. China. The primary parameters of the generator are listed in Table 2, and the stator winding connection of Phase $A$ is indicated in Figures 3(c) and 3(d).

For the electromagnetic force FEA, the 3D transient solution type is selected, and the physical model is shown in Figure 3(e). The stator winding includes four parts, namely, the line part, the joint, the involute part, and the nose part, of which the later three form the end winding, as shown in Figure 3(f). The line parts are laid in double layers in the slots and are defined as upper bar/line and lower bar/line, respectively. The end part extends outside the stator core and forms a basket-shape. Since each coil is composed of an upper bar and a lower bar, for clarification, each winding is marked by the slot number of the upper bar. For example, Winding 1 refers to the winding that is composed of the upper bar in Slot 1, the lower bar in Slot 9 (see Figure 4), and the end part, which connects these two line parts. Moreover, the excitation current is set to DC $1.8 \mathrm{~A}$ in the coupling circuit of armature winding. As shown in Figures 3(g) and $3(\mathrm{~h})$, there are three types of grids in meshing, and the total number of mesh elements is 146787 . The "length based" grid is used for both cores and windings, and the "surface approximation based" grid is also chosen for windings 
TABle 1: Amplitude of the former 6 force harmonics.

\begin{tabular}{lccc}
\hline Component & $\begin{array}{c}\text { Normal condition } \\
\left(\text { Line: } \times 0.5 \Lambda_{0}^{2} l^{2} v / z,\right. \\
\left.\text { End: } \times 0.5 k_{e} \Lambda_{0}^{2} l v \sin \theta_{k} / z\right)\end{array}$ & $\begin{array}{c}\text { RISC } \\
\left(\text { Line: } \times 0.5 \Lambda_{0}^{2} l^{2} v / z,\right. \\
\left.\text { End: } \times 0.5 k_{e} \Lambda_{0}^{2} l v \sin \theta_{k} / z\right)\end{array}$ & Amplitude varying tendency \\
\hline DC component & $\begin{array}{l}\text { Line: } F_{c}^{2}, \\
\text { End: } F_{c}^{2} \cos p \alpha_{k}\end{array}$ & $\begin{array}{l}\text { Line: } F_{c s}^{2}, \\
\text { End: } F_{c s}^{2} \cos p \alpha_{k}\end{array}$ & Decreased \\
$\omega_{r}(16.67 \mathrm{~Hz})$ & 0 & Line and end: $F_{c s} F_{d 2}+F_{c s} F_{d 4}$ & Increased \\
$2 \omega_{r}(33.33 \mathrm{~Hz})$ & 0 & Line and end: $F_{c s} F_{d 1}+F_{c s} F_{d 5}$ & Increased \\
$3 \omega_{r}(50 \mathrm{~Hz})$ & 0 & Line and end: $F_{c s} F_{d 6}$ & Increased \\
$4 \omega_{r}(66.67 \mathrm{~Hz})$ & 0 & Line and end: $F_{c s} F_{d 1}$ & Increased \\
$5 \omega_{r}(83.33 \mathrm{~Hz})$ & 0 & Line and end: $F_{c s} F_{d 2}$ & Increased \\
$6 \omega_{r}(100 \mathrm{~Hz})$ & $F_{c}^{2}$ & Line and end: $F_{c s}^{2}$ & Decreased \\
\hline
\end{tabular}

TABle 2: Key parameters of MJF-30-6 prototype generator.

\begin{tabular}{lc}
\hline Parameter & Value \\
\hline Rated capacity & $30 \mathrm{kVA}$ \\
Rated voltage & $400 \mathrm{v}$ \\
Rated rotating speed & $1000 \mathrm{rpm}$ \\
Number of pole pairs & 3 \\
Connection mode of stator winding & $2 \mathrm{Y}$ \\
Coil pitch & 8 \\
Power factor & 0.8 \\
Operating temperature & $75^{\circ} \mathrm{C}$ \\
Indexing slots of rotor & 42 \\
Real slots of rotor & 30 \\
Number of stator slots & 54 \\
Rated exciting current & $1.8 \mathrm{~A}$ \\
Number of turns in per stator slot & $72 \mathrm{turns}$ \\
Number of turns in per rotor slot & $88 \mathrm{turns}$ \\
Length of rotor & $220 \mathrm{~mm}$ \\
Stack length & $220 \mathrm{~mm}$ \\
Inner diameter of stator & $1230 \mathrm{~mm}$ \\
Outer diameter of stator & $2400 \mathrm{~mm}$ \\
Inner diameter of rotor & $500 \mathrm{~mm}$ \\
Outer diameter of rotor & $1228.3 \mathrm{~mm}$ \\
Air-gap length & $0.85 \mathrm{~mm}$ \\
Stacking factor & 0.95 \\
\hline
\end{tabular}

considering the complexity of the structure. For the air gap between the rotor and stator cores, the "cylindrical gap based" grid is adopted because of the smallness of the space. The solution time is solved for $400 \mathrm{~ms}$, and the step length was set to $0.5 \mathrm{~ms}$. All of the end windings are assigned parameters of force, and the field results of $240 \mathrm{~ms}$ to $400 \mathrm{~ms}$ are saved for postprocessing.

During the experiment, the generator was connected to the power grid. The exciting current was set to $1.8 \mathrm{~A}$, the line voltage was $380 \mathrm{~V}$, and the phase current was $30 \mathrm{~A}$. RISC is set by connecting the short circuit taps $\mathrm{C} 1$ and $\mathrm{C} 2$ through a rheochord, as shown in Figure 3(a). The short circuit degree can be changed by adjusting the value of the rheochord, and it is calculated by

$$
F_{d}=\frac{I_{f}^{\prime}}{I_{f}} \times 25 \%
$$

where $I_{f}^{\prime}$ is the short circuit current, and $I_{f}$ is the exciting current. During the experiment, $I_{f}^{\prime}$ was $0.09 \mathrm{~A}$, and the interturn short circuit degree was $1.25 \%$.

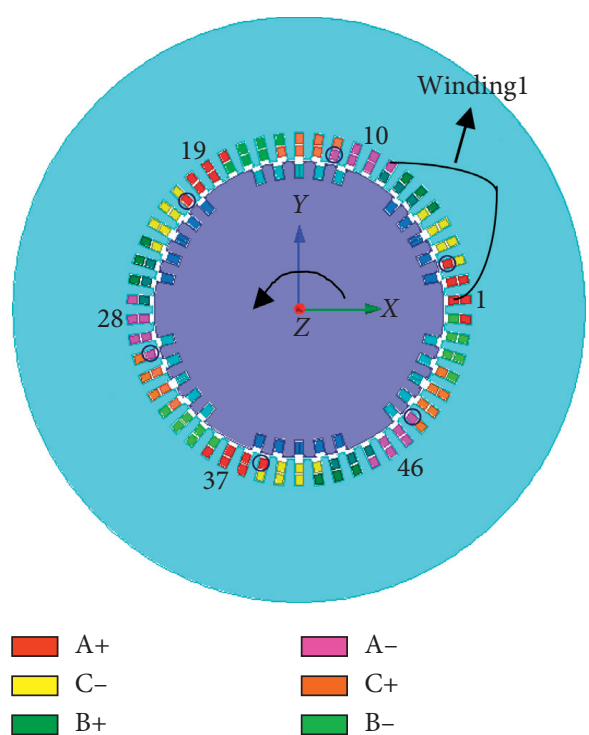

FIgURE 4: Most dangerous insulation damage windings, which are in black circles.

Three PCB accelerometers with very little volume and mass are fixed to the same stator end winding bar. One was set in radial direction to acquire the radial vibration signal, one was set in the tangential direction for the tangential vibration, and the other was set in the axial direction to acquire the axial vibration signal, as shown in Figure 3(b).

3.2. Results and Discussion. Since the three-phase windings are symmetrically distributed, the electromagnetic force on the three-phase windings should be similar as well. Limited by the calculating resource, only Phase- $\mathrm{A}$ windings are calculated as presentation.

The MFD on the stator winding is shown in Figures 5(a) and 5(b). It indicates that the MFD on the line part is larger than that on the end part since the magnetic field in the end region is generally a leakage field, which has smaller amplitudes. Moreover, it is shown that the occurrence of RISC will decrease the MFD. This result coincides with the previously theoretical analysis because $F_{c s}$ is smaller than $F_{c}$, as indicated in equations (1) and (7), and Figures 1(a) and 1(b). And it can be further verified by the current, which is a significant reflect of MFD, as illustrated in Figures 5(c) and $5(d)$. 


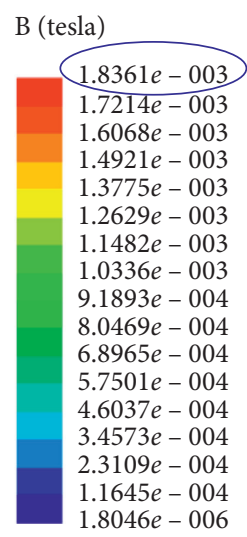

Time $=0.36 \mathrm{~s}$

Speed $=999.999999 \mathrm{rpm}$

Position $=0.000000 \mathrm{deg}$

(a)

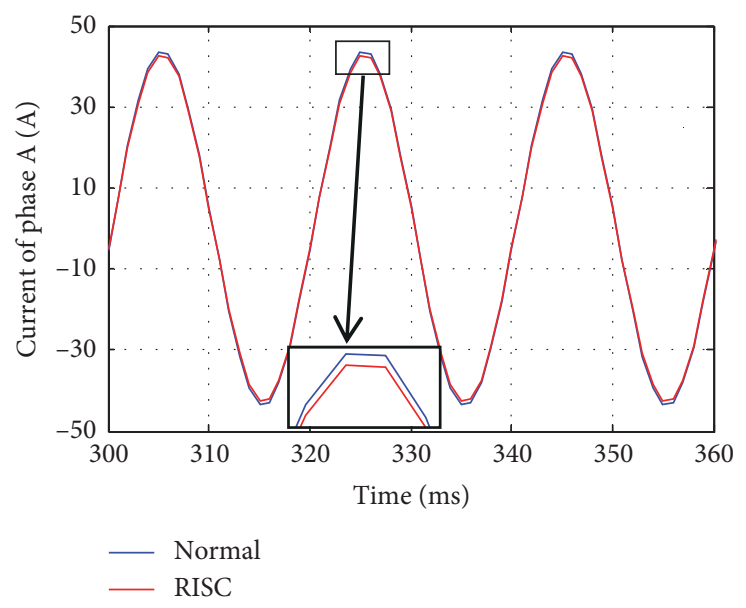

(c)
B (tesla)
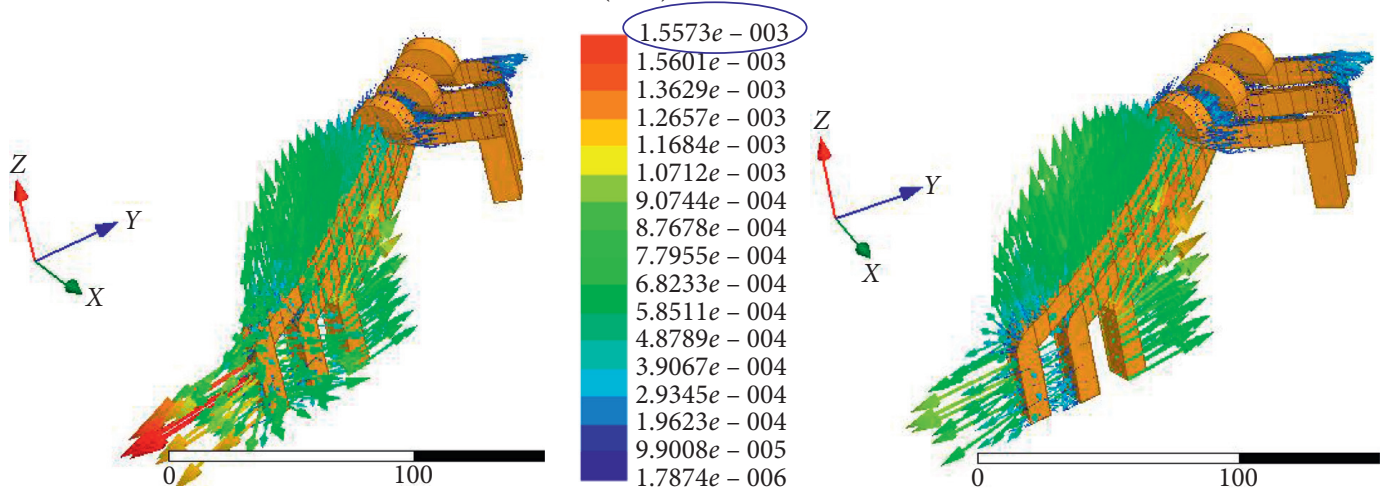

ime $=0.36$

Speed $=999.999999 \mathrm{rpm}$

Position $=0.000000 \mathrm{deg}$

(b)

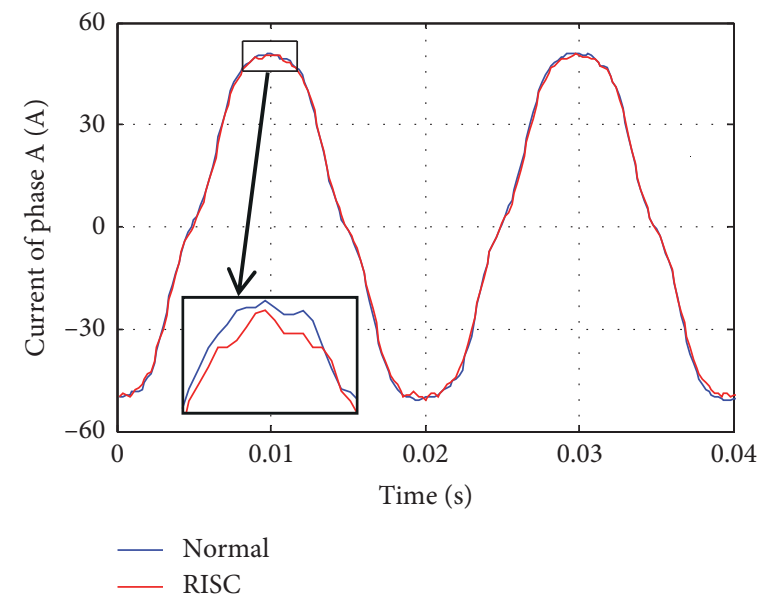

(d)

Figure 5: MFD and current of Phase A: (a) normal MFD, (b) MFD in RISC case, (c) current by FEA, and (d) current by experiment.

The electromagnetic forces are displayed in Figure 6. It is suggested that the electromagnetic force on the joint is the largest, while the nose part is the second, as shown in Figures 6(a) and 6(b). This result is consistent with [19]. The electromagnetic force waves are similar before and after RISC; see Figures 6(c) and 6(d). However, it is distinct that the electromagnetic forces on each winding in the RISC cases are smaller than those in normal conditions, as illustrated in Figures 6(e)-6(g). This can be easily comprehended since $F_{c}>F_{c s}$ and the electromagnetic force $F$ is in proportion to the square of MMF $f$, as shown in equations (10) and (11).

Comparing Figures $6(\mathrm{e})-6(\mathrm{~g})$ with each other, it is suggested that the electromagnetic forces on different windings will be varied. The upper bars have a larger value than the lower bars, since they are closer to the rotor, and the magnetic resistance is smaller (the magnetic resistance is in proportion to the radial air-gap length). The max electromagnetic force on the line part appears on winding 1 upper line, while the max electromagnetic force on the end part occurs on winding 2 . Therefore, slot 1 and its wedge may endure larger stress, and special attention should be paid to it during design and manufacturing. However, the data in Table 3 shows that the max stress does not happen on the end winding 2 because of the complex end involute shape and force directions.

The electromagnetic force spectra of winding 1 are illustrated in Figures 7(a)-7(f). It is shown that, in both the normal and the RISC conditions, the electromagnetic force includes obvious DC and $100 \mathrm{~Hz}$ components. However, as RISC takes place, some weak components, which are 1-5 times the rotor's mechanical rotating frequency $(16.7 \mathrm{~Hz}$, $1000 \mathrm{rpm}$ ), will appear.

For a better comparison, the electromagnetic forces spectra of Phase A windings on the upper line parts (U1, U2, U3), the lower line parts (L1, L2, L3), and the end parts (E1, E2, E3) are illustrated in Figures 7(g)-7(i). Since there are no such harmonics whose angular frequencies are from $\omega_{r}$ to $5 \omega_{r}$ in normal conditions, in Figure 7(h), the force distribution displays only the RISC case. It is suggested that the amplitudes of both the DC and the $100 \mathrm{~Hz}$ components will be decreased as RISC occurs, as illustrated in Figures $7(\mathrm{~g})$ and 7 (i). These conclusions are consistent with the previous theoretic analysis in Table 1. In the meantime, these weak 


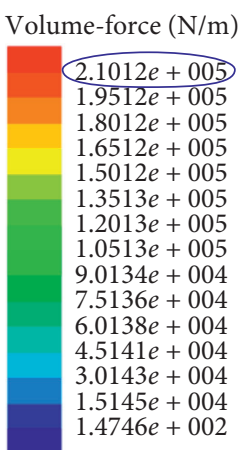

Time $=0.36 \mathrm{~s}$

Speed $=999.999999 \mathrm{rpm}$

Position $=0.000000 \mathrm{deg}$

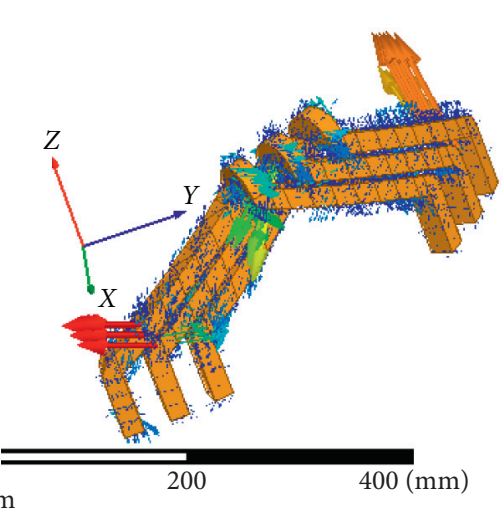

(a)

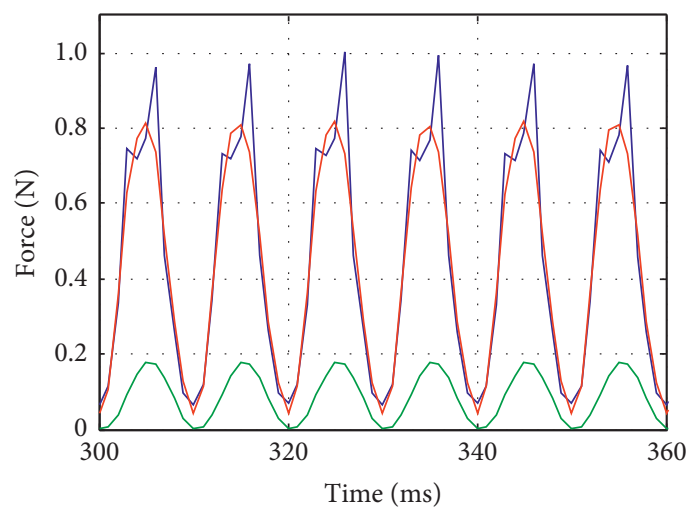

_ Upper line part

_ Lower line part

- End part

(c)

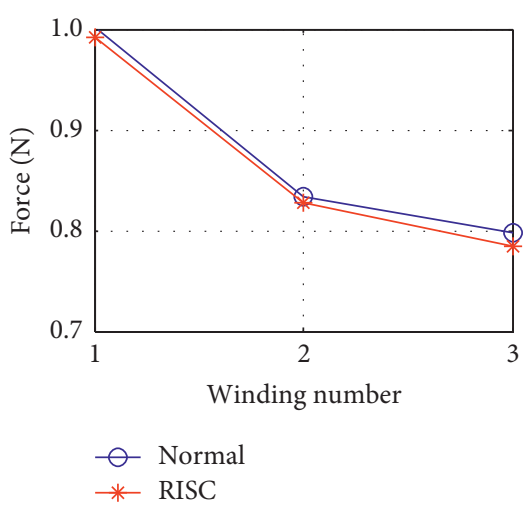

(e)
Volume-force $(\mathrm{N} / \mathrm{m})$

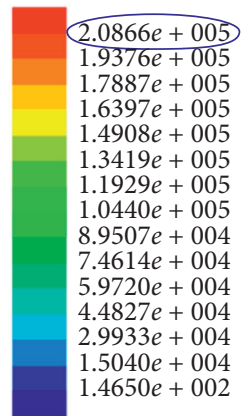

Time $=0.36 \mathrm{~s}$

Speed $=999.999999 \mathrm{rpm}$

Position $=0.000000 \mathrm{deg}$

(b)

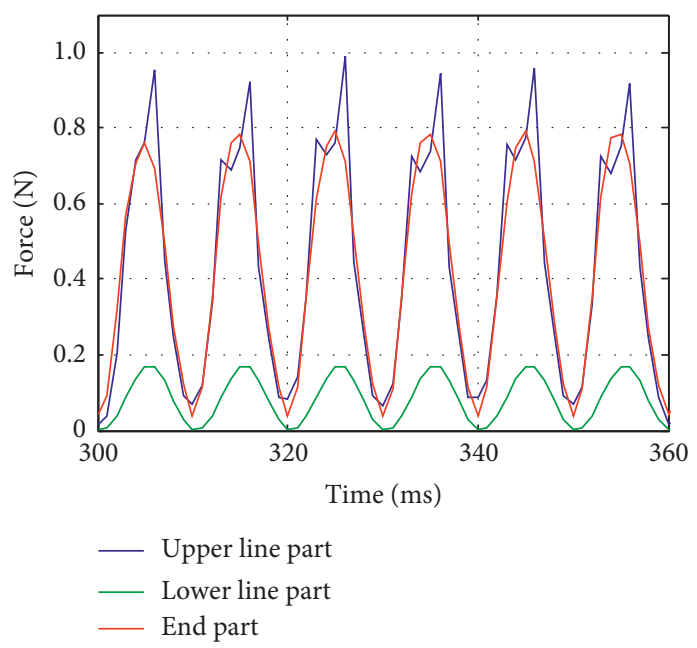

(d)

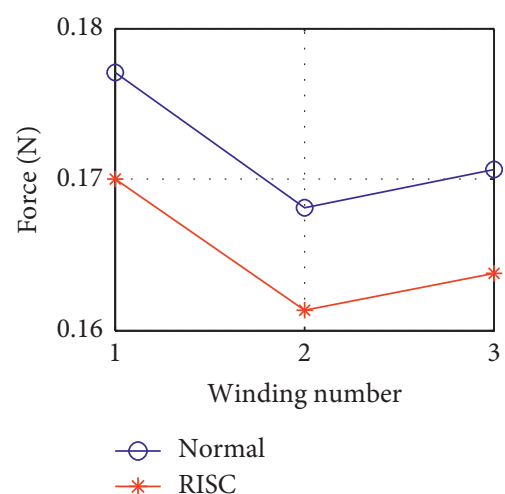

(f)

Figure 6: Continued. 


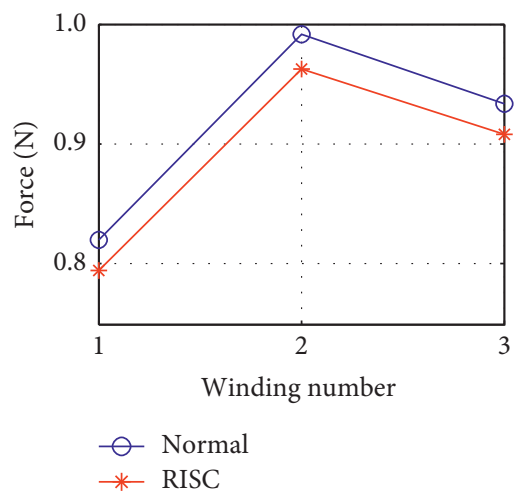

(g)

FIgURE 6: Electromagnetic forces on Phase A windings: (a) normal force distribution, (b) force distribution in RISC case, (c) and (d) electromagnetic force waves of winding 1 before and after RISC, and (e), (f), and (g) max value of force on upper line, lower line, and end part, respectively.

TABLE 3: The maximum of deformation and stress of each winding.

\begin{tabular}{|c|c|c|c|c|c|}
\hline & & Deformation $\left(10^{-7} \mathrm{~m}\right) /$ time $(\mathrm{s})$ & Tendency & Stress $\left(10^{4} \mathrm{pa}\right) /$ time $(\mathrm{s})$ & Tendency \\
\hline Winding 1 & $\begin{array}{c}\text { Normal } \\
\text { RISC }\end{array}$ & $\begin{array}{l}9.187 / 0.0385 \\
9.188 / 0.0385\end{array}$ & Increase & $\begin{array}{c}5.974 / 0.0620 \\
5.928 / 00385\end{array}$ & Decrease \\
\hline Winding 2 & $\begin{array}{c}\text { Normal } \\
\text { RISC }\end{array}$ & $\begin{array}{l}2.1138 / 0.0555 \\
2.1129 / 0.0555\end{array}$ & Decrease & $\begin{array}{l}2.508 / 0.002 \\
2.818 / 0.002 \\
\end{array}$ & Increase \\
\hline Winding 3 & $\begin{array}{c}\text { Normal } \\
\text { RISC }\end{array}$ & $\begin{array}{l}719.3 / 0.0380 \\
736.3 / 0.0380\end{array}$ & Increase & $\begin{array}{c}540 / 0.0380 \\
554 / 0.038\end{array}$ & Increase \\
\hline
\end{tabular}

components on the lower line parts are not as clear as those on the other parts; see Figure $7(\mathrm{~h})$.

The tested vibration result is indicated in Figure 8. It is shown that the harmonic at $100 \mathrm{~Hz}$ has the prominent amplitude. As RISC happens, the amplitude of the key vibration component at $100 \mathrm{~Hz}$ will be decreased. It is consistent with the previously theoretical analysis and electromagnetic force FEA result, as shown in Table 1 and Figure 7(i). Moreover, the vibration is larger in radial than in axial or tangential direction, and this phenomenon is in accordance with the deformation property in the structure FEA simulation, as shown in Figure 9. Because the rotor is rotating at $16.7 \mathrm{~Hz}$, there are some components that are times of the rotating frequency, for example, $50 \mathrm{~Hz}, 68.4 \mathrm{~Hz}$, and so on.

\section{Winding Damage Regularity}

The insulation property will be degraded due to the intensified alternating stress for a long term, and then the fatigue fracture will happen. On the other hand, the winding deformation reflects the vibration amplitude since the vibration is the periodic movement (deformation). So the insulation material will be damaged by the wearing due to the excessive deformation. To study the impact of RISC on the winding stress and deformation, the physical model, as well as two cycles of electromagnetic force density data, was imported to the transient structural module for the mechanical response calculation. The winding material is defined as copper alloy whose yield strength and ultimate strength are $280 \mathrm{MPa}$ and
$430 \mathrm{MPa}$, respectively. The line parts are constrained by fixed supports. Automatic meshing is adopted, and 1082 nodes are generated for each end winding.

Considering that the stress and deformation distributions of the winding will be similarly repeated, only the results of winding 1 are presented as shown in Figures 10 and 11. The maximum values of the deformation and the stress, together with their occurring moments, are listed in Table 3.

As indicated in Figures 10 and 11, the joint and the nose of end winding are the two most dangerous positions because they have the serious stress and the max deformation. The occurrence of RISC will not change these dangerous positions. During practical monitoring, these two positions should be paid more attention since fatigue fracture and insulation wear will most probably start from these two locations. Practically, we also found some damage pictures in these two parts; see Figure 12. The significant countermeasure against insulation damage is that, during the manufacturing/assembling, the nose part is screened with a wear-resistant coating such as grapheme, and the joint is protected with high-strength load reduction kits.

It is suggested from Table 3 that winding 3 endures the most serious stress and deformation, while winding 1 stands the second largest value. The value on winding 2 is much smaller than that on winding 3 . The reason is that windings 1 and 3 are in the phase-shift boundaries, as the armature magnetic fields of the neighboring phases interact with each other. Additionally, it is shown that the RISC will decrease the max stress of winding 1 and deformation of winding 2, while increasing the others. 


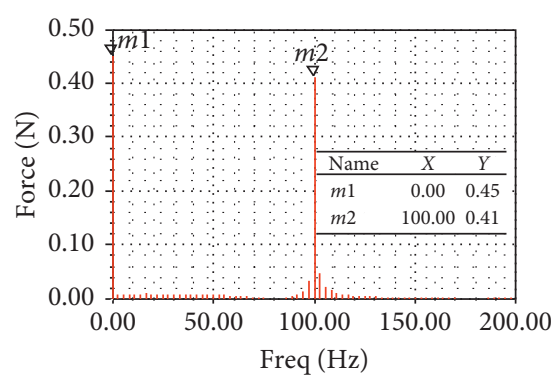

(a)

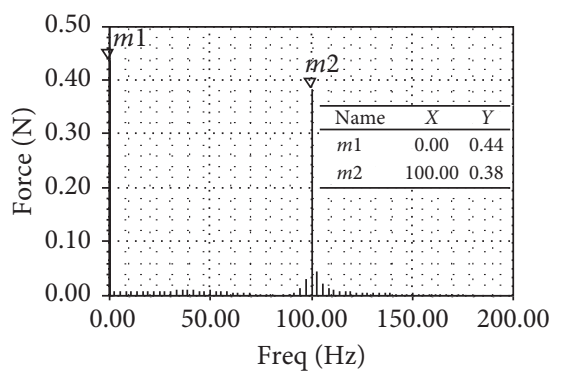

(c)

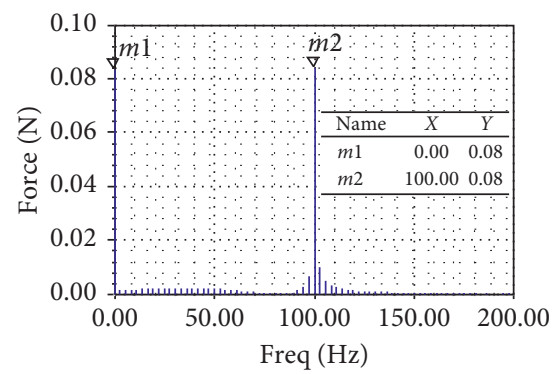

(e)

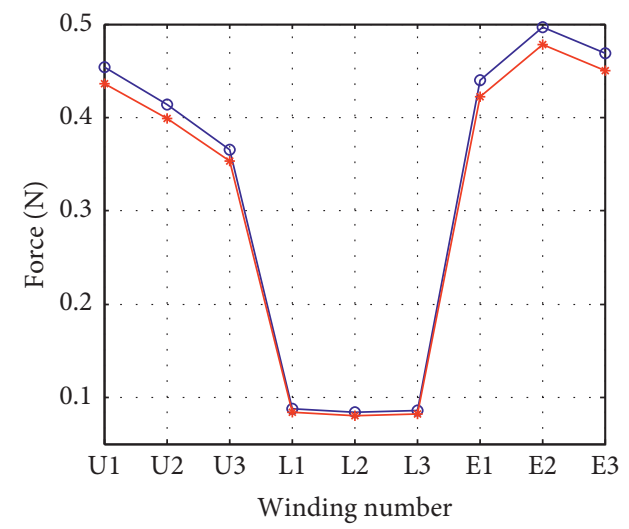

- - Normal

* RISC

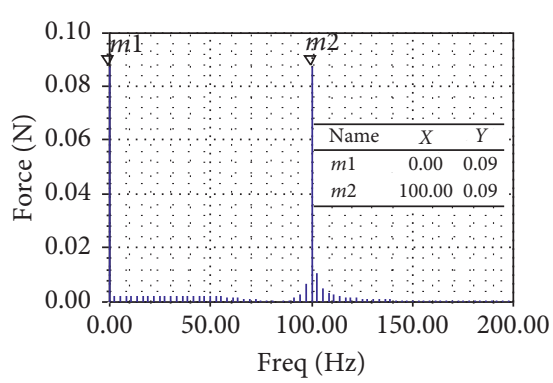

(b)

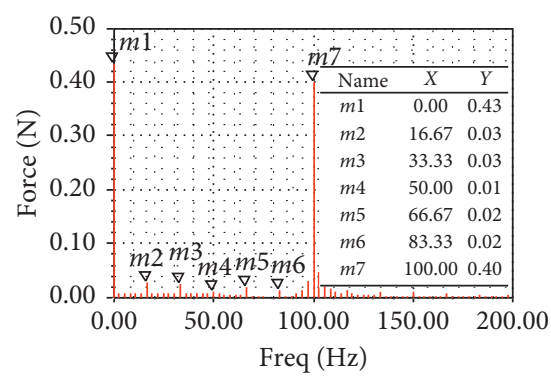

(d)

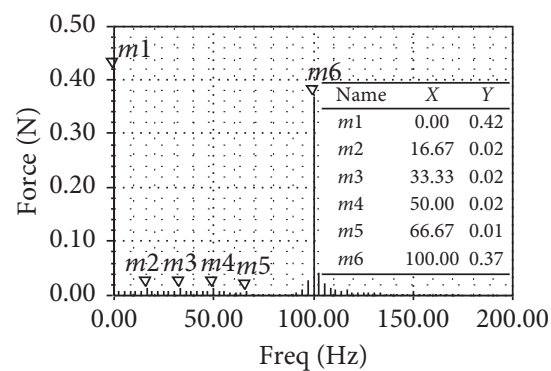

(f)

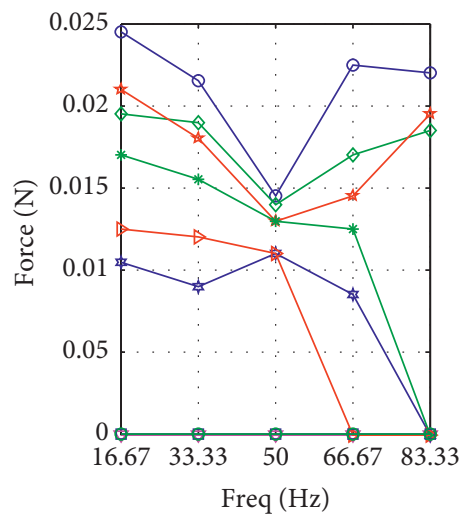

$\begin{array}{ll}\rightarrow \mathrm{U} 1 & \rightarrow \mathrm{E} 2 \\ \rightarrow \mathrm{U} 2 & \rightarrow \mathrm{E} 3 \\ \rightarrow \mathrm{U} 3 & \rightarrow \mathrm{L} 2 \\ \rightarrow \mathrm{L} 1 & -\mathrm{L} 3 \\ \rightarrow \mathrm{E} 1 & \end{array}$

(h)

(g)

FIgUre 7: Continued. 


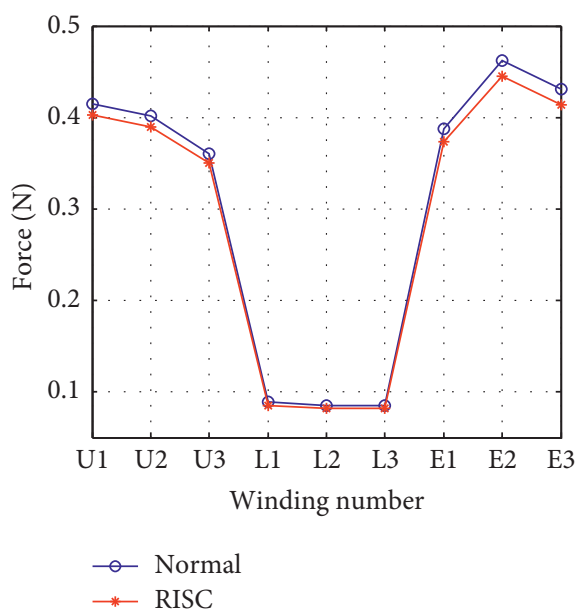

(i)

FIGURE 7: Electromagnetic force spectra: (a-c) winding 1 upper line, lower line, and end part in normal case, respectively, (d-f) winding 1 upper line, lower line, and end part after RISC, respectively, (g) DC component comparison, (h) force amplitude in RISC case for components from $\omega_{r}$ to $5 \omega_{r}$, and (i) amplitude comparison at $6 \omega_{r}(100 \mathrm{~Hz})$.

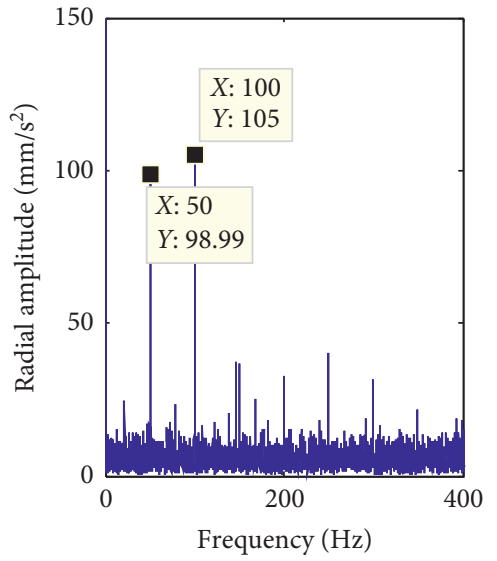

(a)

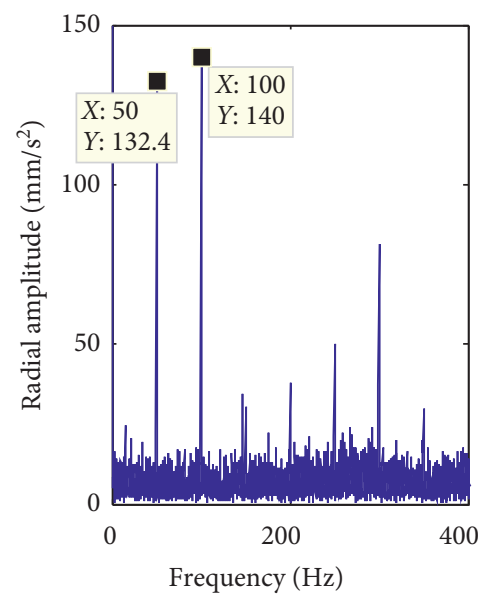

(d)

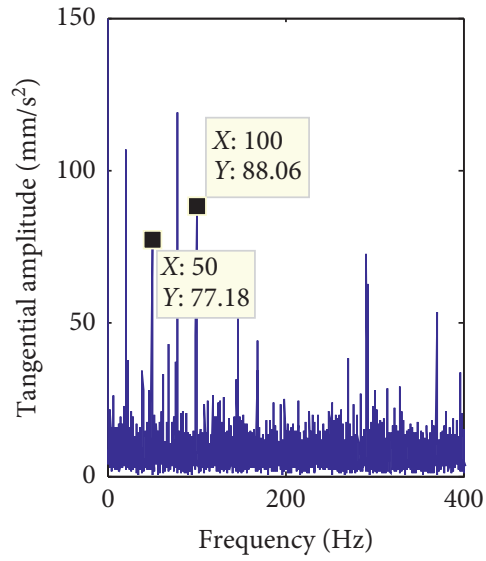

(b)

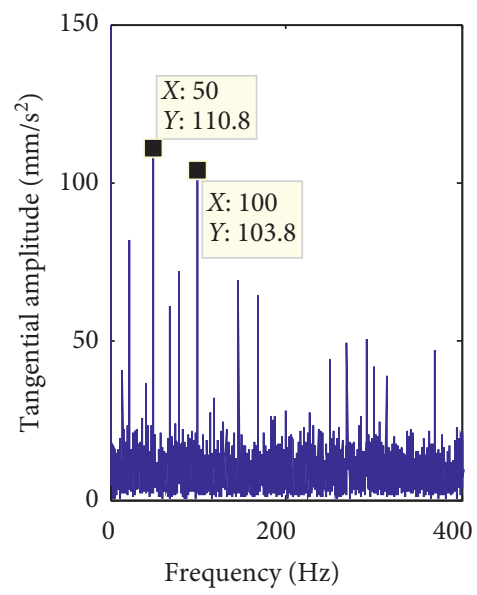

(e)

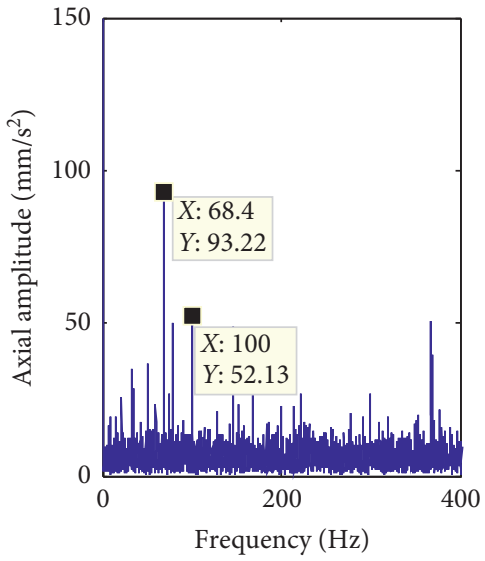

(c)

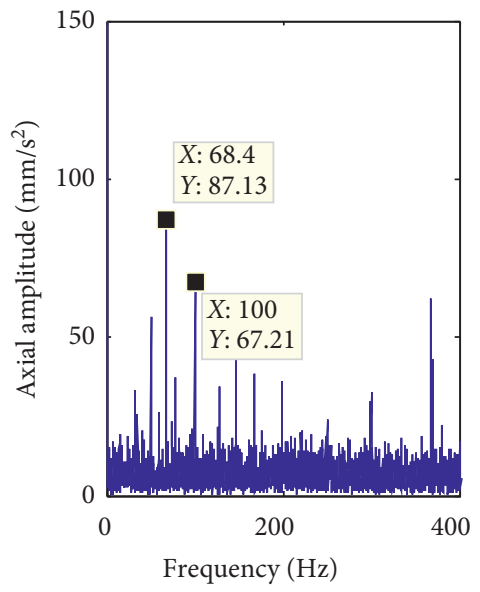

(f)

FIGURE 8: Stator end winding vibration: (a), (b), and (c) vibration acceleration spectra in normal, respectively, (d), (e), and (f) vibration acceleration spectra after RISC, respectively. 


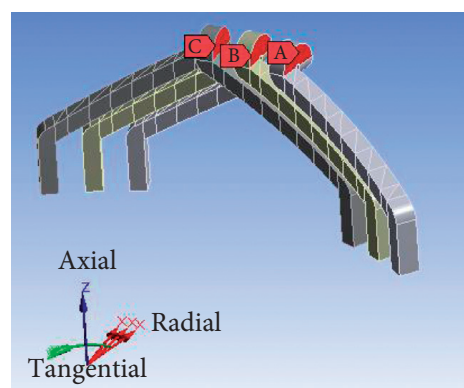

(a)

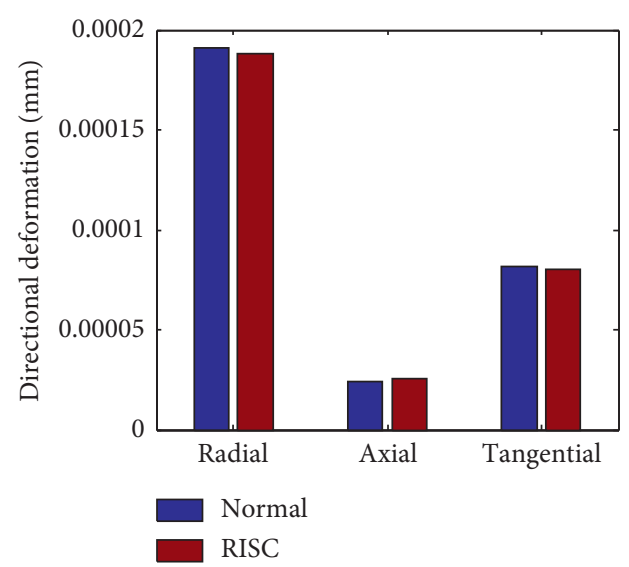

(c)

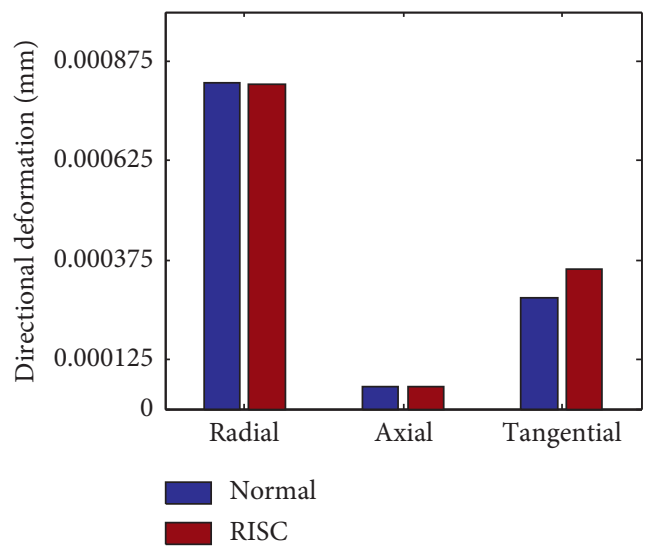

(b)

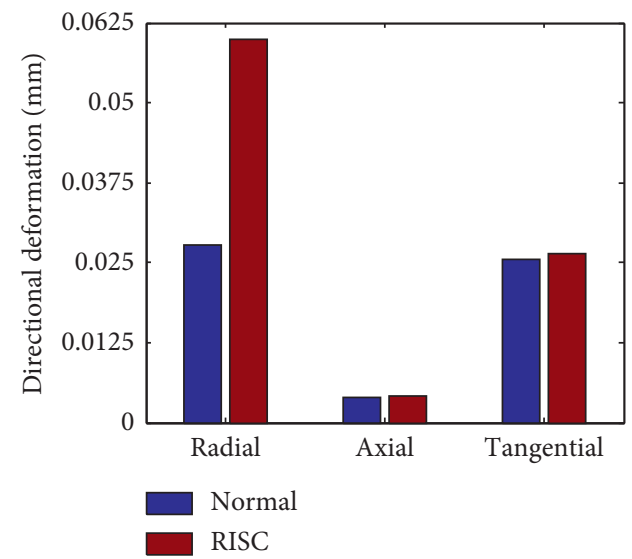

(d)

FIGURE 9: Directional deformation amplitude of nose part before and after RISC: (a) probe positions, (b) winding 1, (c) winding 2, and (d) winding 3.

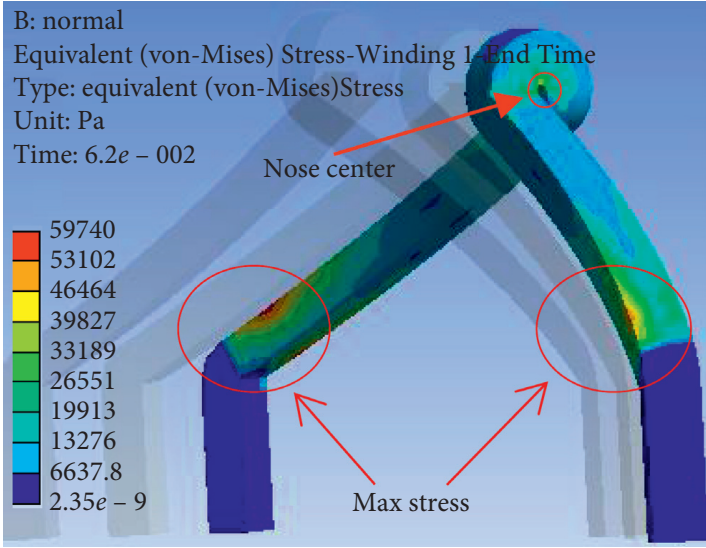

(a)

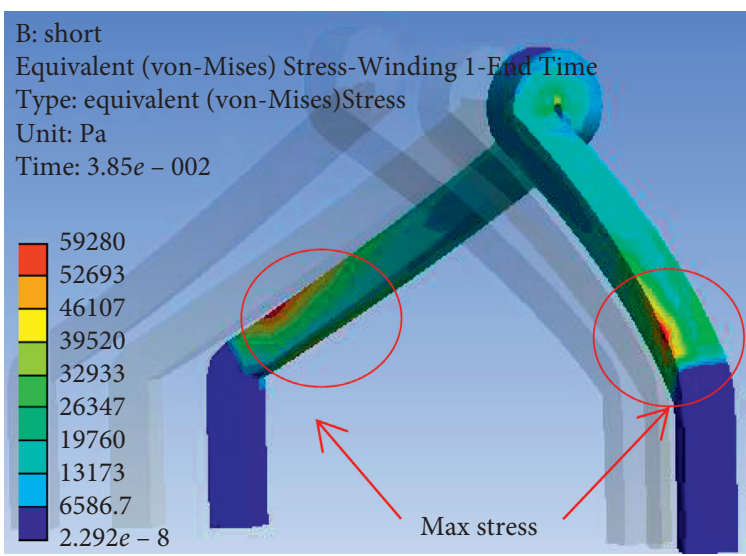

(b)

Figure 10: Maximum stress of end winding 1 before and after RISC: (a) normal condition, (b) RISC.

In actual generators, for instance, hydrocool generators, the nose is not only the electrical connecting part, but also the connecting part for the cooling water. So this part is always the weak point. Figures 8 and 10 indicate that, for the nose part, the max stress and deformation occur on center and top, respectively, so the nose fatigue fracture will begin from the center, and nose insulation wear will start from the top.

To better study the deformation components in the radial, axial, and tangential directions of the nose part, we 


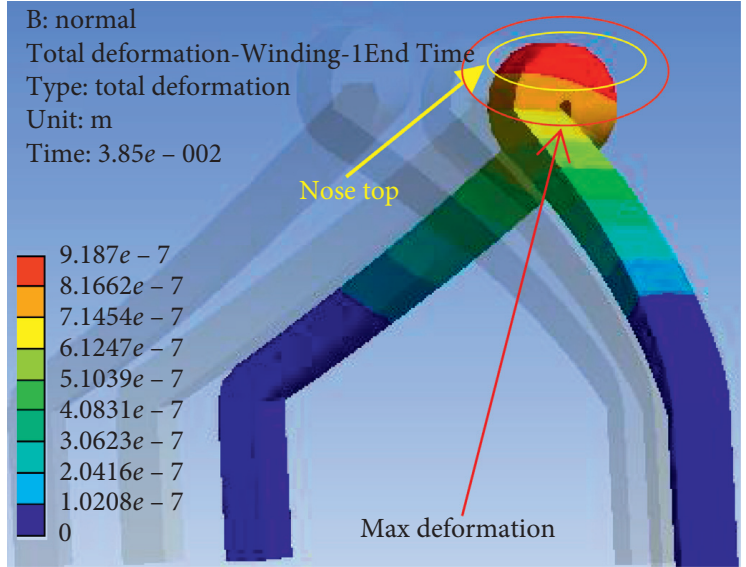

(a)

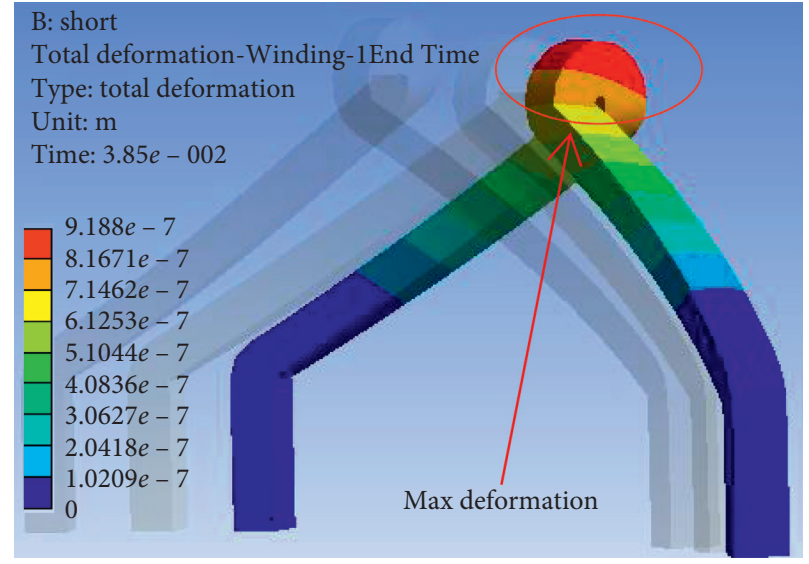

(b)

FIgUre 11: Maximum deformation of end winding 1 before and after RISC: (a) normal condition, (b) RISC case.

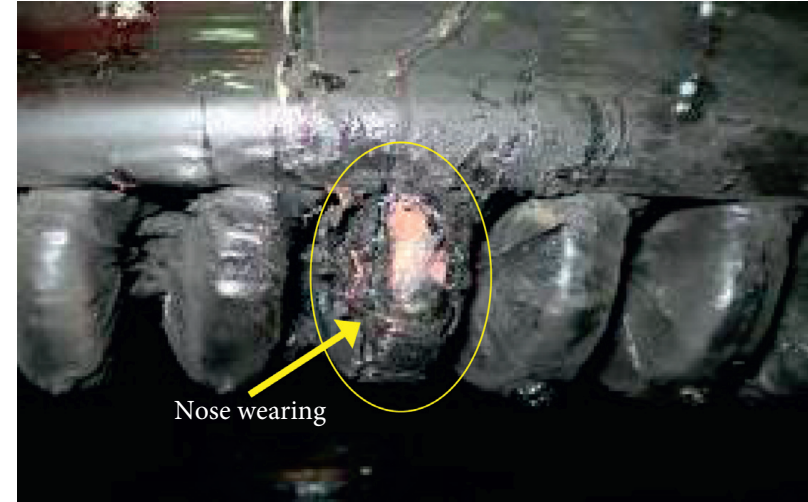

(a)

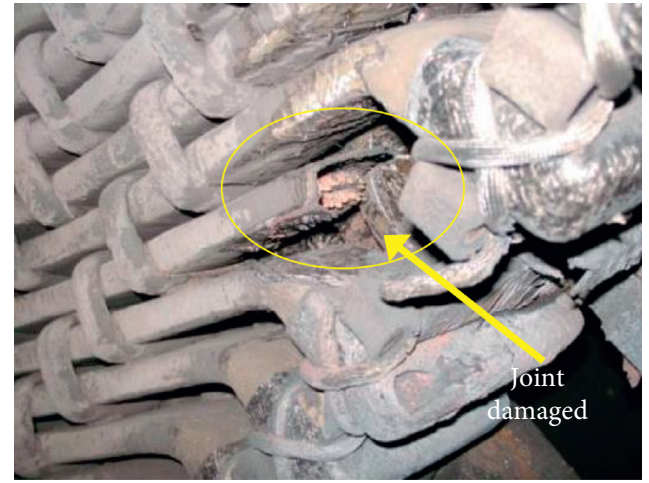

(c)

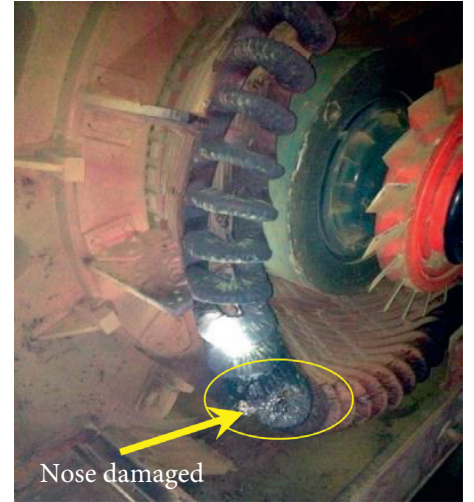

(b)

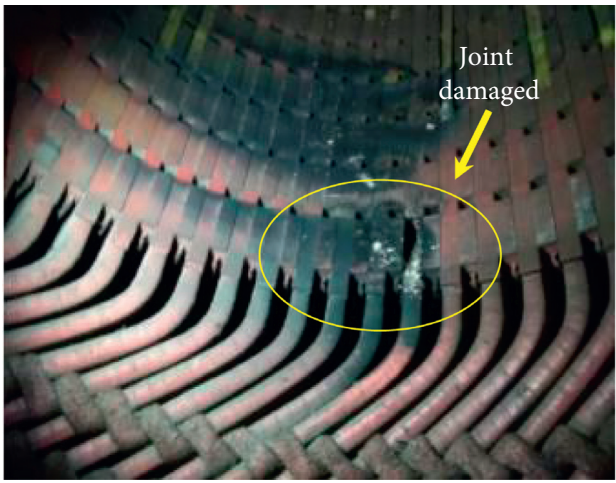

(d)

FIgURe 12: Pictures of nose and joint damage: (a) and (b) nose part damage, and (c) and (d) joint part damage.

illustrate these directional deformations before and after RISC for the three windings of Phase A, respectively, as shown Figure 9. It is found that the axial deformation on the nose of winding 1 will be enlarged by RISC, while the radial and the tangential deformations will generally keep stable. For winding 2, the deformation components in the three directions will all be slightly decreased. On the contrary, the radial deformation for winding 3 will be greatly increased, while the tangential and the axial deformations will generally keep the same. Additionally, the deformation is larger in radial than in tangential direction. Actually, In view of the double-layer lap structure of the end windings, the insulation wearing in the same layer is mainly caused by the radial and the axial deformations, while the insulation wearing in different layers depends on the tangential and the axial deformations. Consequently, the winding wearing 
would be more serious in the same layer than different layers.

According to Table 3 and Figure 9, in one phase, the nose part on the last winding, which touches the main flux lines later than others along the rotor's rotating direction, will be the most dangerous position for insulation wearing. The most dangerous positions for Phases $\mathrm{B}$ and $\mathrm{C}$ have the same regularity, as the black circled windings illustrated in Figure 4.

\section{Conclusions}

This paper carries out a detailed investigation on the electromagnetic force behaviors of stator windings before and after RISC in multi-pair-pole synchronous generator. Primary conclusions obtained from theoretical analysis, the finite element calculation, and the experimental study are drawn as follows.

The mathematical expressions show that the electromagnetic force includes both DC and AC components. Normally, the $2 p \omega_{r}$ harmonic is the prominent electromagnetic force component that will excite the winding to vibrate at $100 \mathrm{~Hz}$. The occurrence of RISC will decrease the $2 p \omega_{r}$ harmonic but will bring in new fractional harmonics, which are times of the rotor's mechanical rotating frequency $\omega_{r}$. Consequently, the stator winding will have more vibration components, which may be close to its own natural frequencies and lead to a sympathetic vibration. By these analytical electromagnetic force formulas, the vibration developing tendency can be assessed fast, and therefore, they are potential to be applied for the stator winding monitoring.

Finite element analysis and experimental study are carried out on a MJF-30-6 prototype generator, which is of 6 poles and $1000 \mathrm{rpm}$. It is found that the upper bar will endure larger electromagnetic forces than the lower bar. There are two positions that are most probably to get the insulation damage. One is the nose part, which endures both the largest deformation and the second largest stress. The other is the joint part (the connection between the line winding and the end winding), which stands the most intensified stress. In the same phase, the inter-phase winding (neighboring winding between two phases), especially these end ones of the phases, will experience much larger deformations and stresses than the other windings. To better protect the windings against insulation damage, we recommend that the nose part and the joint be screened with wear-resistant coating and high-strength load reduction kits, respectively.

Although the research content is based on synchronous generators, other types of synchronous machine have the same structure and working principle as synchronous generators. After a long period of operation, synchronous machinery may come into being RISC caused by vibration, insulation aging, and other factors. Therefore, the study is applied to the most synchronous machinery that uses wound rotor. Since the findings in this paper include the insulation damage regularity and propose the possible countermeasure, they will be beneficial for the manufacturing technique improvement and the monitoring convenience. Meanwhile, the study achievements obtained in this paper are highly potential to be employed as a basis for the further investigations in other related problems for the similar electric machines.

Moreover, further study will be based on the shape of stator winding [see Figure 3, and (8)] in the electromechanical property, and it will be beneficial for the condition monitoring and fault diagnosis, as well as the calculation improvement during design session.

\section{Data Availability}

The data used to support the findings of this study are available from the corresponding author upon request.

\section{Conflicts of Interest}

All the authors declare that there are no conflicts of interest regarding the publication of this paper.

\section{Acknowledgments}

This work was supported by the National Natural Science Foundation of China (51777074), the Hebei Provincial Natural Science Foundation (E2020502032), the Chinese Fundamental Research Funds for the Central Universities (2017MS146, 2018YQ03), and the Hebei Provincial Top Youth Talent Support Program ([2018]-27).

\section{References}

[1] A. Merkhouf, B. F. Boueri, and H. Karmaker, "Generator end windings forces and natural frequency analysis," in Proceedings of the IEEE International Electric Machines and Drives Conference, 2003 (IEMDC'03), vol. 1, pp. 111-114, Madison, WI, USA, June 2003.

[2] B. Sanosian, P. Wendling, T. Pham, and W. Akaishi, "Electromagnetic forces on coils and bars inside the slot of hydrogenerator," in Proceedings of the 2019 IEEE Energy Conversion Congress and Exposition (ECCE), pp. 1754-1760, Baltimore, MD, USA, September 2019.

[3] S. Wan, X. Yao, and L. Dou, "Computation and characteristic analysis on electromagnetic force and nose torque of stator end windings in turbo-generator," Journal of Vibration, Measurement \& Diagnosis, vol. 34, no. 5, pp. 920-925, 2014, in Chinese.

[4] A. Ghaempanah and J. Faiz, "Impact of rotor winding and stator stepped end core on magnetic force distribution on stator end-winding of turbogenerators," in Proceedings of the 2015 IEEE Jordan Conference on Applied Electrical Engineering and Computing Technologies (AEECT), pp. 1-6, Amman, Jordan, November 2015.

[5] K.-C. Kim and S.-J. Hwang, "Comparison study of Biot-Savart law and 3D FEM of electromagnetic forces acting on end windings," in Proceedings of the Digests of the 2010 14th Biennial IEEE Conference on Electromagnetic Field Computation, p. 1, Chicago, IL, USA, May 2010.

[6] A. A. Tatevosyan and V. V. Fokina, "The study of the electromagnetic field of the synchronous magnetoelectric generator," in Proceedings of the 2015 International Siberian Conference on Control and Communications (SIBCON), pp. 1-4, Omsk, Russia, May 2015. 
[7] L. Yan-ping and Y. Qing-shuang, "Analysis and calculation of electromagnetic force on damper windings for $1000 \mathrm{MW}$ hydro-generator," in Proceedings of the 2011 International Conference on Electrical Machines and Systems, pp. 1-6, Beijing, China, August 2011.

[8] Y. Liang, Z. Guo, X. Bian, C. Wang, D. Wang, and L. Gao, "Novel optimization evaluation of the asymmetric-paths winding considering the electromagnetic force characteristics in AC machines," in Proceedings of the 2019 22nd International Conference on Electrical Machines and Systems (ICEMS), pp. 1-6, Harbin, China, August 2019.

[9] R. D. Stancheva and I. I. Iatcheva, "3-D electromagnetic force distribution in the end region of turbogenerator," IEEE Transactions on Magnetics, vol. 45, no. 3, pp. 1000-1003, 2009.

[10] R. Stancheva and I. Iatcheva, "Dynamic behaviour investigation of electromagnetic force densities," Journal of Materials Processing Technology, vol. 161, no. 1-2, pp. 258-262, 2005.

[11] Z. Chong, H. Song, and Y. Yongming, "Analysis of electromagnetic forces on involute part of end winding in a 1550 MW nuclear generator," in Proceedings of the 2017 IEEE 2nd Advanced Information Technology, Electronic and Automation Control Conference (IAEAC), pp. 1-4, Chongqing, China, March 2017.

[12] Y. Wang, J. Zhang, B. Zhou, Y. Wang, Y. Ni, and J. Pan, "Magnetic shunt design and their effects on transformer winding electromagnetic forces," Iranian Journal of Science and Technology, Transactions of Electrical Engineering, vol. 43, no. 1, pp. 97-105, 2019.

[13] A. Ghabeli, M. Yazdani-Asrami, and A. Gholamian, "A novel unsymmetrical multi-segment concentric winding scheme for electromagnetic force and leakage flux mitigation in HTS power transformers," IEEE Transactions on Applied Superconductivity, vol. 25, no. 6, pp. 1-10, 2015.

[14] D. Scott, S. Salon, and G. Kusik, "Electromagnetic forces on the armature end windings of large turbine generators I-steady state conditions," IEEE Transactions on Power Apparatus and Systems, vol. 100, no. 11, pp. 4597-4603, 1981.

[15] J. Wang, R. Qu, Y. Liu, and J. Li, "Study of multiphase superconducting wind generators with fractional-slot concentrated windings," IEEE Transactions on Applied Superconductivity, vol. 24, no. 3, pp. 1-6, Article ID 5202106, 2014.

[16] F. Xiong and X. Wang, "Development of a multi-pitch unequal-turn-coil wound rotor for the brushless doubly-fed generator," in Proceedings of the 2013 International Conference on Electrical Machines and Systems (ICEMS), pp. 668671, Busan, Republic of Korea, October 2013.

[17] A. Stermecki, O. Biro, G. Ofner, and H. Lang, "Numerical simulation of electromagnetic and mechanical phenomena in the end-winding region of three-phase induction machines," E\&I Elektrotechnik Und Informationstechnik, vol. 128, no. 5, pp. 167-173, 2011.

[18] Y. Fang, X. Bao, Q. lv, X. Cheng, and Y. He, "Analysis of electromagnetic force distribution on end winding of electrical submersible motor during starting transient operation," IEEE Transactions on Magnetics, vol. 49, no. 10, pp. 53415345, 2013.

[19] H. C. Jiang, Y. L. He, and G. J. Tang, "A comprehensive analysis on transient electromagnetic force behavior of stator windings in turbo-generator," Mathematical Problems in Engineering, vol. 2018, Article ID 4189609, 16 pages, 2018.

[20] R. Albanese, F. Calvano, G. Dal Mut et al., "Coupled three dimensional numerical calculation of forces and stresses on the end windings of large turbo generators via integral formulation," IEEE Transactions on Magnetics, vol. 48, no. 2, pp. 875-878, 2012.

[21] Y. Zhao, B. Yan, C. Zeng, S. Huang, C. Chen, and J. Deng, "Optimal scheme for structural design of large turbogenerator stator end winding," IEEE Transactions on Energy Conversion, vol. 31, no. 4, pp. 1423-1432, 2016.

[22] S. Nadarajan, S. K. Panda, B. Bhangu, and A. K. Gupta, "Hybrid model for wound-rotor synchronous generator to detect and diagnose turn-to-turn short-circuit fault in stator windings," IEEE Transactions on Industrial Electronics, vol. 62, no. 3, pp. 1888-1900, 2015.

[23] W. Yucai and L. Yonggang, "Diagnosis of rotor winding interturn short-circuit in turbine generators using virtual power," IEEE Transactions on Energy Conversion, vol. 30, no. 1, pp. 183-188, 2015.

[24] M. Valavi, K. G. Jorstad, and A. Nysveen, "Electromagnetic analysis and electrical signature-based detection of rotor inter-turn faults in salient-Pole synchronous machine," IEEE Transactions on Magnetics, vol. 54, no. 9, pp. 1-9, 2018.

[25] J. Yun, S. Park, C. Yang et al., "Comprehensive monitoring of field winding short circuits for salient pole synchronous motors," IEEE Transactions on Energy Conversion, vol. 34, no. 3, pp. 1686-1694, 2019.

[26] Y. Li, Y. Sun, L. Wang, and H. Li, “The criterion on inter-turn short circuit fault diagnose of steam turbine generator rotor windings," in Proceedings of the 2007 International Conference on Electrical Machines and Systems (ICEMS), pp. 1050-1054, Seoul, Republic of Korea, October 2007.

[27] S. Wan, Y. Li, H. Li, and G. Tang, "The new diagnosis method of rotor winding inter-turn short circuit fault and imbalance fault based on stator and rotor vibration characteristics," in Proceedings of the 2005 International Conference on Electrical Machines and Systems, vol. 3, pp. 2207-2210, Nanjing, China, September 2005.

[28] W. Shuting, L. Yonggang, L. Heming, and T. Guiji, “A compositive diagnosis method on turbine-generator rotor winding inter-turn short circuit fault," in Proceedings of the 2006 IEEE International Symposium on Industrial Electronics, pp. 1662-1666, Montreal, Canada, July 2006.

[29] Y.-G. Li, Y.-J. Zhao, L. Chen, and X. Ji, "Fault diagnosis of rotor winding inter-turn short circuit in turbine-generator based on BP neural network," in Proceedings of the 2008 International Conference on Electrical Machines and Systems, pp. 783-787, Wuhan, China, October 2008.

[30] W. Yucai, M. Qianqian, and C. Bochong, "Fault diagnosis of rotor winding inter-turn short circuit for sensorless synchronous generator through screw," IET Electric Power Applications, vol. 11, no. 8, pp. 1475-1482, 2017.

[31] Q. Meng and Y. He, "Mechanical response before and after rotor inter-turn short-circuit fault on stator windings in synchronous generator," in Proceedings of the 2018 IEEE Student Conference on Electric Machines and Systems, pp. 1-7, Huzhou, China, December 2018.

[32] Y.-L. He, M.-Q. Ke, and G.-J. Tang, "Analysis and simulation on the effect of rotor interturn short circuit on magnetic flux density of turbo-generator," Journal of Electrical EngineeringElektrotechnicky Casopis, vol. 67, no. 5, pp. 323-333, 2016.

[33] Y.-L. He, M.-Q. Ke, and F.-L. Wang, "Effect of static eccentricity and stator inter-turn short circuit composite fault on rotor vibration characteristics of generator," Transactions of the Canadian Society for Mechanical Engineering, vol. 39, no. 4, pp. 767-781, 2015. 
[34] Y.-L. He, W.-Q. Deng, B. Peng et al., "Stator vibration characteristic identification of turbogenerator among single and composite faults composed of static air-gap eccentricity and rotor interturn short circuit," Shock and Vibration, vol. 2016, Article ID 5971081, 14 pages, 2016. 